\title{
Trends in Chemical Wood Surface Improvements and Modifications: A Review of the Last Five Years
}

\author{
Pierre Blanchet (D) and Simon Pepin*
}

check for updates

Citation: Blanchet, P.; Pepin, S.

Trends in Chemical Wood Surface

Improvements and Modifications: A Review of the Last Five Years.

Coatings 2021, 11, 1514. https://

doi.org/10.3390/coatings11121514

Academic Editor: Ludmila

B. Boinovich

Received: 19 October 2021

Accepted: 6 December 2021

Published: 9 December 2021

Publisher's Note: MDPI stays neutral with regard to jurisdictional claims in published maps and institutional affiliations.

Copyright: (c) 2021 by the authors. Licensee MDPI, Basel, Switzerland. This article is an open access article distributed under the terms and conditions of the Creative Commons Attribution (CC BY) license (https:/ / creativecommons.org/licenses/by/ $4.0 /)$.
Natural Sciences and Engineering Research Council of Canada (NSERC) Industrial Chair on Ecoresponsible Wood Construction, Université Laval, 2425 Rue de l’Université, Québec, QC G1V 0A6, Canada; Pierre.Blanchet@sbf.ulaval.ca

* Correspondence: simon.pepin.1@ulaval.ca

\begin{abstract}
Increasing the use of wood in buildings is regarded by many as a key solution to tackle climate change. For this reason, a lot of research is carried out to develop new and innovative wood surface improvements and make wood more appealing through features such as increased durability, fire-retardancy, superhydrophobicity, and self-healing. However, in order to have a positive impact on the society, these surface improvements must be applied in real buildings. In this review, the last five years of research in the domain of wood surface improvements and modifications is first presented by sorting the latest innovations into different trends. Afterward, these trends are correlated to specifications representing different normative, ecologic and economic factors which must be considered when expecting to introduce a wood treatment to the market. With this review, the authors hope to help researchers to take into consideration the different factors influencing whether new innovations can leave the research laboratory or not, and thereby facilitate the introduction of new wood surface treatments in the society.
\end{abstract}

Keywords: wood; surface; improvements; modifications; treatments; coatings; plasma modification; surface impregnation

\section{Introduction}

Although wood is already a well-appreciated construction material, it is of primary importance to properly protect it and reach its full potential on the market. Indeed, it is crucial that the use of wood in buildings increases, as it is a renewable and bio-based material that can store large amounts of carbon dioxide and substitute for less eco-friendly materials such as steel and concrete [1,2]. For that matter, the use of wood in construction was even designated as a key tool to fight climate change by the FAO [3]. In order to achieve this goal, efforts must be deployed to improve attitudes of the public and architects toward its presence in buildings.

A central issue with wood is its combustibility, which is a subject of high legislative importance and a major source of concerns for the public. Wood can however be exposed to other sources of degradation according to its use (indoor, outdoor with or without exposition to rainfalls, ground contact, marine environment, etc.) [4]. Wood exposed outdoor can be weathered by numerous abiotic elements such as wind, dust, rain, and sunlight. Both air moisture and liquid water can be absorbed by the wood's hygroscopic nature and produce dimensional changes, which will lead it to cup, warp and crack [5]. If suitable conditions are met, living organisms such as decay fungi, molds, insects, and marine borers may feed on its structural components or on the nutrients contained in its parenchyma [4]. All of these will inevitably modify its chemical and physical properties, as well as its physical appearance, which will reduce its lifespan. This reality is of high ecological and economical importance, as defective wood pieces need to be replaced and make wood less competitive against other materials. 
Good building practices can prevent the degradation of wood by reducing its exposition to some sources of degradation. Choosing high quality materials, such as naturally durable species or heartwood, can also help to extend the service life of wood products. However, the price and availability of durable species, as well as the increasing importance of fast-growing, lower quality lumber call for other alternatives [6]. In order to make wood more performant toward degradation, wood treatments become a very reliable solution. Many treatments have been developed over the last decades, including thermal and chemical modifications [7-10], thermo-mechanical densification [11,12], and impregnation [13-15]. Wood can be impregnated through vacuum/pressure methods to introduce biocidal, hydrophobic, and fire-retardant materials deeply in its structure $[16,17]$. Finally, wood can simply be protected on its surface with a variety of organic, mineral, or metallic coatings $[18,19]$, or by different surface treatments.

Coatings and surface treatments can have different functions, from protecting wood from degradation to imbuing it with new and attractive properties. A major aspect of the research of wood surface protection is hydrophobization, since water is omnipresent and it can cause many kinds of defects, from cracking to promoting fungal growth [5]. A material is considered hydrophobic when the contact angle of water on its surface is above $90^{\circ}$, and superhydrophobic when its contact angle is over $150^{\circ}$ and its roll-off angle (the tilt required for the droplet to slide) is below $10^{\circ}$ [20]. While hydrophobicity is fairly easy to achieve, superhydrophobicity requires a rough and carefully designed micro-/nanoscale architecture and a very low surface free energy. This property is hard to maintain over a long time, as the micro-/nanoscale structure is quite fragile. Self-healing properties can be quite useful to maintain superhydrophobicity, as it can repair the micro-/nanoscale structure after physical damages such as cutting and abrasion [21]. Self-healing can be achieved in two ways, either by having a reserve of mobile hydrophobic materials to fill the damages or by reestablishing the initial structure through stimuli. A great side effect of superhydrophobicity is that it promotes other interesting surface properties such as anti-sludging and self-cleaning [22]. These properties rise from the fact that contaminants dissolved in water drops will hardly be left on surfaces on which water cannot adhere, and that water-soluble contaminants will be washed off when water slides away. Another way to obtain a self-cleaning surface is by improving its photocatalytic properties, allowing it to decompose organic compounds.

Photostability is another important property of wood coatings and surface modification. Ultraviolet rays from the sun promote the weathering of wood by degrading the polymeric constituents of its surface, mostly lignin [23]. This phenomenon results in a pale-looking wood with a decreased adhesion and can lead to the loss of its coating, which would expose wood to more sources of degradation [24]. Opaque and semi-transparent coatings are less prone to photodegradation, as their pigments readily absorb the UV rays. However, if a transparent coating is used in order to appreciate the natural aesthetics of wood, then UV-blockers are needed to prevent its weathering [25].

As mentioned earlier, fire protection is a central stake in wood protection [26]. The protection of wood from fire includes delaying the initial burning time, reducing the amount of smoke and heat released upon burning, and slowing down the spread of the flames [27]. It is often assured by impregnation with fire retarding materials, but it can also be achieved through surface protection. Some of the methods to reach this objective include inorganic coatings [28], modified organic coatings and fire-retardant fillers [19]. Other important characteristics can be brought about by surface treatment such as improved mechanical properties (hardness, abrasion resistance), chemical stability, and resistance to biodegradation.

As presented by Dimitrakellis and Gogolides, numerous methods exist to coat and modify the surface of wood, many of which can be divided in two groups: bottom-up and top-down [20]. Bottom-up methods involve the gradual building of the surface protection and include methods such as layer-by-layer deposition and chemical vapor deposition. Conversely, top-down methods shape a bulk of material, or wood itself, into the desired 
end-product; such approaches include plasma modification. Commonly, surface coatings and modifications will rely on techniques such as dipping, spraying, brushing, chemical grafting, electroless deposition, chemical plating, and hydrothermal deposition.

The wide variety of treatment methods and chemicals used in wood-surface protection is indeed of great scientific interest and is needed to find solutions suitable for the different uses of wood. However, the large amount of knowledge produced on the subject can be confusing to readers trying to plan future research, while looking for the most promising treatments for a given application. In this review, a summary of the last five years of research in the domain of wood surface improvements and modifications will first be presented in order to establish the major trends. Subsequently, these trends will be analyzed from different perspectives, including some normative, environmental, and economical aspects associated with wood protection, in order to see which ones perform the best in each category. The aim of this review is not to decide which treatments are worthwhile and which ones should be abandoned, but rather to have a reflection on the strengths and weaknesses of the current research trends while discussing some key elements associated with the deployment of new wood protection technologies in the industry.

\section{Methodology}

The object of this publication is to review the last five years of literature in wood surface improvements and modifications, ranging from 2016 to 2020. To give an accurate description of the very latest trends, the publications up to 20 May 2021, were also included in the review.

To find as many relevant publications as possible, complementary methods were used to investigate the literature. First, a systematic approach was adopted to screen five databases (Compendex, Inspec, GEOBASE, GeoRef, and Knovel) on Engineering Village. Then, a research strategy based on keywords was carried out on Google Scholar, while publications and reviews were screened to find additional publications.

In order to keep the number of publications to a reasonable level and to allow good comparability between the treatments, strict exclusion criteria were chosen (Table 1). As a general statement, only treatments performed on solid wood were considered. In this way, the performances of the wood-surface treatments are not affected by gluing, pretreatments, and transformations, allowing for a better comparison between the different studies. Likewise, treatments performed on wood-based materials such as panels, woodplastic composites, and transparent wood were excluded. Also, treatments reaching deeper than the first few layers of cells of the wood specimens, such as acetylation, thermomodification, thermo-mechanical densification, and transparent wood were excluded, as they cannot be considered surface treatments. Finally, the review focuses principally on wood used in construction; as such, treatments aimed at other uses such as water-oil separation or wooden artifacts restoration were also excluded to keep common thread between the publications.

As a result of searching in five databases at the same time, the number of publications found on Engineering Village included a lot of duplicates and, consequently, was very high. After removing the duplicates from multiple databases and between the different queries, 745 publications remained. The titles of the publications were first screened for relevance to the subject of the review; many titles specified containing excluded content (thermo-modified wood, pressure impregnation, etc.) or were simply irrelevant, leading to the rejection of 522 studies. The abstract and, when needed, the core of the 223 remaining publications were then screened for eligibility, of which 90 were included in the review. The research on Google Scholar and the publications cited in other texts led to a total of 803 publications; after removing the duplicates and the publications already found in the systematic research, 376 new publications were screened, 122 of which were included in the review. The keywords of the different queries are detailed in Table 2 and the PRISMA flow diagram is presented in Figure 1. 
The 212 publications found in the literature were divided in three categories: coatings, surface modification and surface impregnation. Coatings were the most studied method for the protection of wood surfaces, with 144 publications. A total of 52 publications were included in the surface modifications and the last 16 described surface impregnation. The results were not compared between the studies, as the methods employed to test the properties of wood surfaces differed a lot between the studies.

Table 1. Justifications for the exclusion criteria.

\begin{tabular}{|c|c|}
\hline Exclusion Criteria & Reason \\
\hline Thermo-modified wood & \multirow{5}{*}{$\begin{array}{l}\text { These treatments were excluded from the review as they affect the treated wood deeply } \\
\text { below the surface. Also, treatments performed on pre-modified wood specimens were } \\
\text { excluded as their chemical and mechanical properties may be different and the } \\
\text { performances of the treatments may not be comparable with treatments on solid wood. } \\
\text { Glued wood products (glulam, plywood, OSB, etc.) were excluded as their mechanical } \\
\text { properties and permeability may be affected. }\end{array}$} \\
\hline Chemically modified wood & \\
\hline Thermo-mechanically densified wood & \\
\hline Transparent wood & \\
\hline Glued wood product & \\
\hline Impregnated wood & $\begin{array}{l}\text { Wood products impregnated before the surface treatment were not considered, as their } \\
\text { chemical properties may be altered. }\end{array}$ \\
\hline Deep impregnation & $\begin{array}{l}\text { Only surface impregnation was relevant to the review; methods allowing deep } \\
\text { longitudinal or radial impregnation were rejected. }\end{array}$ \\
\hline Treatments unrelated to construction timber & $\begin{array}{l}\text { To keep a certain logic between the publications presented, only the papers related to } \\
\text { timber treatments were included. }\end{array}$ \\
\hline
\end{tabular}

Table 2. Keywords of the queries on Engineering Village and Google Scholar.

\section{Engineering Village}

(1)-Wood AND surface AND (modification OR treatment)

(2)-(1) AND (coatings OR impregnation OR plasma OR nanotechnology)

(3)-Wood AND surface AND (fire OR hydrophocity OR hydrophilicity OR uv OR self-healing OR hardness OR abrasion OR biodegradation)

\section{Google}
(a)-Wood AND surface
(b)-(a) AND improvement
(c)-(a) AND properties
(d)-(a) AND modification
(e)-(a) AND treatment
(f)-(d) AND treatment

(g)-(a) AND impregnation
(h)-(a) AND plasma
(i)-(h) AND treatment
(j)-(h) AND modification
(k)-(g) AND treatment

(l)-(g) AND modification

(m)-(l) AND treatment

(n)-(a) AND nanotech*

(o)-Wood AND (coatings OR finishes)

(p)-(a) AND chemical AND densification

(q)-(a) AND (coatings OR finishes)

(4)-(2) And (fire OR hydrophocity OR hydrophilicity OR uv OR self-healing OR hardness OR abrasion OR biodegradation)
(r)-Wood AND self-healing
(s)-(o) AND nanotech*
(t)-(a) AND (Modification OR Plasma OR coating OR finishes OR chemical) AND (treatment OR impregnation OR nanotech* OR densification 


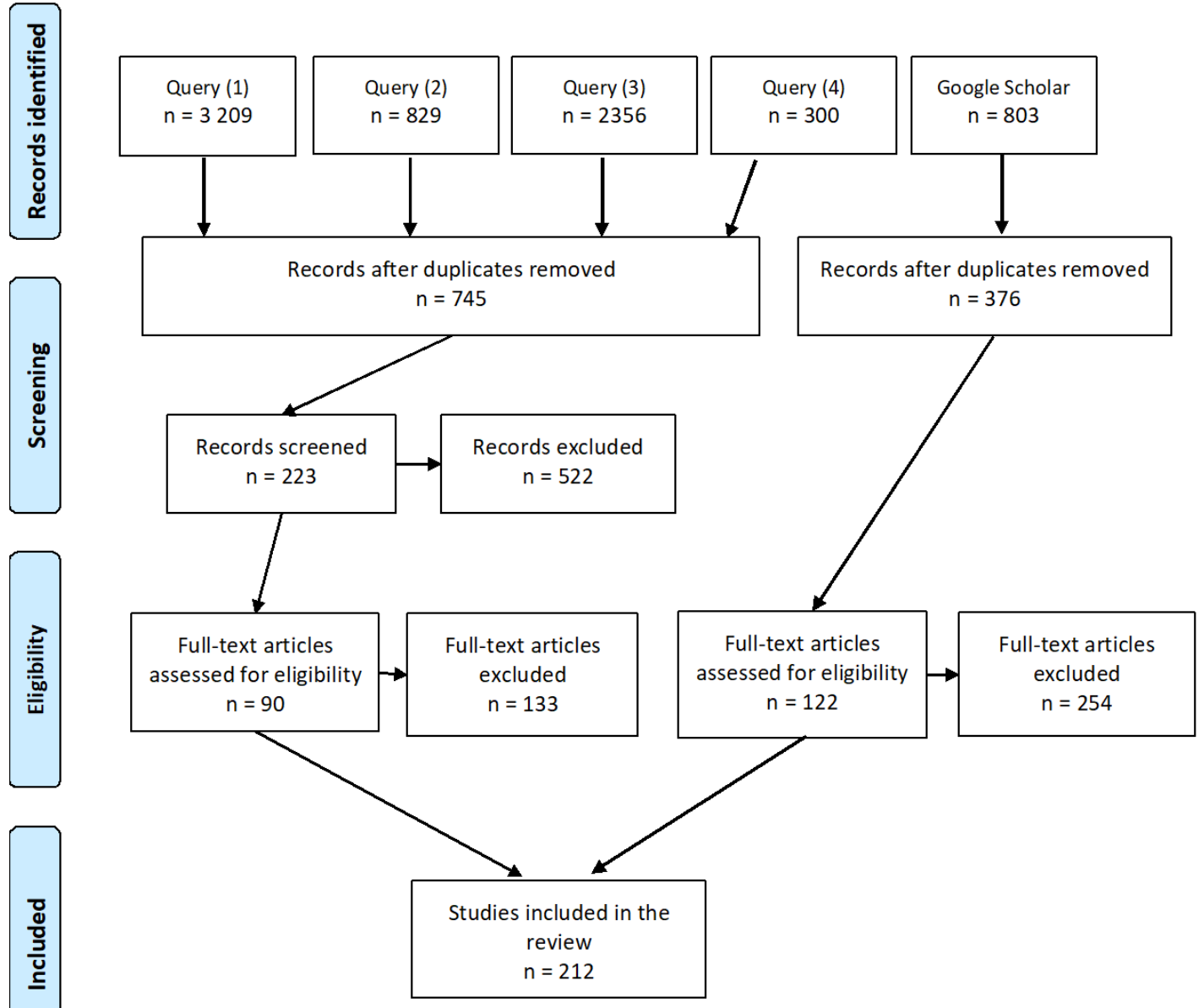

Figure 1. PRISMA flow diagram for the two searches strategies [29].

\section{Trends of the Last Five Years}

In this section, the publications covering the last five years of research in the domains of wood surface improvement and modification are presented. They are grouped in three main categories, namely coatings, surface modification and surface impregnation; because of the large number of papers published on the coatings and surface modifications, these are further divided into a few subcategories. Thereafter, the publications in each subcategory are sorted into different trends. Due to the large number of publications presented into the review, only some publications in each trend are detailed, while the other publications are simply presented. The detailed publications are usually chosen to represent the different properties obtained into each trend, because they performed particularly well, or because they present interesting features (bio-based materials, very high durability, etc.). Although extensive characterization of the surfaces and coatings is usually carried out in the original publications, this review focuses more specifically on the practical performances of the surface treatments (hydrophobicity, thermal stability, photostability, durability, etc.) in order to keep this section at a reasonable length. However, readers are encouraged to read the full publications to learn more about important elements such as transparency, gloss, roughness, chemical composition, and surface morphology.

\subsection{Coatings}

Coatings were the most intensively studied methods for the protection of wood surfaces during the last five years. A total of 144 papers were found on this subject, using diverse materials and application methods to improve surface properties, such as 
hydrophobicity, hardness, abrasion resistance, photostability, thermal stability, self-healing, self-cleaning and more.

\subsubsection{Organic Coatings}

Organic coatings are very common in wood protection, including waxes, oils, and filmforming resins such as acrylics, alkyds and polyurethanes. While they can be improved with additives, a popular approach found in the latest literature to enhance the properties of film-forming organic coatings was to use strategic reactives to change key properties of the resin itself. Different fire-retardant coatings were reported using phosphorus containing monomers or reactive diluents [30-33]. Lokhande et al. used glycidyl methacrylate, piperazine, and cyclic ethylene chlorophosphite to develop a diacrylate reactive diluent yielding UV-cured coatings with increased thermal resistance, hardness, hydrophobicity and stain resistance [34]. They found that the thermal properties of the coating would improve with the content of their reactive diluent, a concentration of $25 \%$ increasing the weight-loss temperatures, the heat-index resistance (from $149.7^{\circ} \mathrm{C}$ to $184.0^{\circ} \mathrm{C}$ ), the practical char yield at $600{ }^{\circ} \mathrm{C}(7.12 \%$ to $22.21 \%)$, and the limiting-oxygen index ( $23 \%$ to $33 \%$ ) when compared to the same coating without the reactive diluent. A similar coating was developed by Mulge et al. using epoxy acrylate oligomers and phenylphosphonic dichloride [35]. However, it was found that while a higher P content would improve the thermal stability of the coating, it would eventually impair its physical properties. In a similar way, Paquet et al. created self-healing, film-forming coatings by using acrylic monomers and oligomers containing many hydroxyl groups [36]. By using 2-hydroxyethyl methacrylate and an aliphatic urethane acrylate oligomer (Ebecryl 4738), the obtained polymer that could completely heal a $5 \mu \mathrm{m}$ deep scratch or regain $83 \%$ of the gloss lost to abrasion after being heated to $80^{\circ} \mathrm{C}$ for two hours. Another use for this practice was to build fast UV-curing acylic [37] and polyurethane-acrylate [38] formulations.

The same strategy was used to prepare more environmentally friendly coatings by using bio-based materials as a reactive. Raychura et al. prepared polyurethane coatings by reacting diisocyanates with fatty amides of mahua [39] and peanut [40] oils. The obtained wood coatings scored $100 \%$ on a cross-cut adhesion test, $1 \mathrm{H}$ or $2 \mathrm{H}$ on pencil hardness tests, and had a good stability to weak acids, water and $\mathrm{NaCl}$ solutions. Interestingly, wood coatings with good resistance to termites and/or white rot fungi could be obtained by reacting the starch from a yam (Dioscorea hispida sp.) with polyvinyl alcohol [41] or polyacrylamide [42]. Another antiseptic coating was prepared by Dixit et al. with citric acid and glycidyl methacrylate [43], which had high adhesion (5B), pencil hardness (6H), solvent resistance and a $15 \mathrm{~mm}$ zone of inhibition against the bacteria Staphylococcus aureus. It will be shown later in the review that cellulose nanocrystals (CNCs) were extensively studied as additives for organic coatings; Kong et al. [44], however, innovated by using $\mathrm{CNCs}$ as a reactive to imbue a waterborne polyurethane coating with a higher hardness and resistance to abrasion. They found that using only $0.1 \%$ of CNCs modified with 2,2,6,6tetramethylpiperidine-1-oxyl (TEMPO) in their coating would increase its tensile strength and tensile elongation by $59 \%$ and $55 \%$, respectively. More bio-based chemicals were studied by other workers, including soybean oil [45], rapeseed oil [46], and biosourced alcohols and acids [47].

Some organic coatings were prepared using very distinctive methods and could not be categorized into a specific trend, but still deserve some attention [48-50]. Janesch et al. dip-coated spruce in tung oil, bee wax, or a mix of both, before sifting sodium chloride $(\mathrm{NaCl})$ on the freshly coated wood [51]. The $\mathrm{NaCl}$, which created a micro-/nanoscale architecture into the coating, was removed one week later by rinsing with distilled water. The resulting wood surface was $100 \%$ natural, food safe and had a contact angle with water of $161^{\circ}$, but was not considered superhydrophobic as its roll-off angle was extremely high Zhang et al. designed a biogel coating based on chitosan, gelatin and glycerol that had quite a low adhesion (1.4 MPa), but some very interesting features [52]. It could completely heal medium damages under heating, be reused after being scrapped from the wood 
and dissolved in water, and be colored with water-soluble dyes. A 3-layers coating was produced on beech wood with a polydopamine primer, an hydroxyapatite second layer, and a chitosan topcoat made from shrimp wastes [53]. The composite coating showed good hydrophobicity (contact angle $=130^{\circ}$ ), photostability and resistance to seawater. After 6 months of immersion in the sea, the treated samples showed lower chemical degradation, color changes $\left(E^{*}=12.68\right.$ vs. 22.24$)$ and damages from barnacles than the controls samples. Liu and $\mathrm{Hu}$ prepared polystyrene colloidal microspheres with different acrylate-based copolymers [54]. Once casted on aspen, the very densely arranged microsphere exhibited different colors, such as green, orange and red. Other unique organic coatings were developed by using materials, such as chitosan oligomers, vegetable oil, castor oil and lignin to protect wood from decay fungi [55], fire [56], and photodegradation [57,58].

\subsubsection{Additives in Organic Coatings}

While it was shown in the previous section that organic wood coatings could be improved by using the appropriate reactives, another great way to obtain performant coatings is through the inclusion of functional additives. Organic, bio-based materials have been the subject of much research over the last 5 years. They are very interesting substances for wood protection, as they biodegrade upon leaching. Cellulose nanocrystals and nanofibrils received a lot of attention due to their potential to improve the mechanical properties of the softer oil- or resin-based organic coatings [59-63]. Tian et al. prepared a renewable UV-cured polyester methacrylate coating based on L-lactide and $\varepsilon$-caprolactone, containing $0 \%$ to $7.5 \%$ of cellulose nanocrystals (CNCs) [64]. The properties of the resulting composite coating changed proportionally to the concentration of CNCs, with an increase in bending strength, bending modulus, hardness and water contact angle, but a decreased tensile strength and elongation at break. At a 7.5\% content of CNCs, the coating had a grade 3 adhesion, a $5 \mathrm{H}$ pencil hardness and a $103^{\circ}$ contact angle. Veigel et al. incorporated $1 \%$ of cellulose nanofribrils (CNFs) to linseed oil after modification with acetic anhydride and (2dodecen-1-yl)succinic anhydride to increase their solubility [65]. While the beech substrate coated with this varnish had the same initial hydrophobicity as the samples treated without the CNFs, the reduction of the hydrophobicity caused by multiple cycles of abrasion with a Taber Abraser was much slower for the CNFs containing formulations, showing a greatly reduced loss of oil. Kaboorani et al. modified cellulose nanocrystals (CNCs) with hexadecyltrimethylammonium bromide to improve their compatibility with a UV-cured acrylic resin [66-68]. They found that a loading of 3\% of CNCs significantly enhanced the pencil hardness, tensile strength, modulus of elasticity, and thermal stability of the coating, while reducing its mass loss following abrasion and water vapor uptake and transmission rate. Cheng et al. found that adding CNCs and silver nanoparticles to a polyurethane coating exhibited a synergistic effect toward the antimicrobial properties of the coating, while also improving its adhesion [69]. Tree extracts were another type of additives that received a lot of attention, this time to imbue wood with better photostability [70,71]. Acrylic coatings containing condensed tannins and modified tannins were prepared by Grigsby to protect radiata pine [72] before exposition to natural and accelerated weathering. A loading of less than $0.5 \%$ of tannins was sufficient to extend the coating's life up to $20 \%$ more than commercially available hindered amine light stabilizers (HALS) and phenolic stabilizers could. Tomak et al. coated Scots pine with water-based acrylics containing tannins from different woods species in the presence [73] or absence [74] of metallic oxides. They found that after $1512 \mathrm{~h}$ of artificial weathering, their coatings could outperform the commercial reference coating in terms of color changes and chemical degradation. It appeared that the lower concentrations of extractives were more effective against UV degradation, and that the interactions between the different tannin and oxides types were completely random. Waterborne acrylic containing CNF and bark extractives was prepared by Huang et al., which yielded both photostability and better mechanical properties (hardness and abrasion resistance) [75]. Finally, Yan et al. prepared acrylic wood coatings containing delignified wheat-straw powder, either raw or after calcination [76]. The 
resulting coatings showed good resistance to molds, especially when the wheat straw was calcined.

Some non-bio-based, organic wood coating additives were also studied over the last five years, sometimes under the form of microcapsules. Zhu et al. prepared ureaformaldehyde microcapsules loaded with thermochromic material to make color-shifting wood under thermal stimuli [77]. A waterborne varnish containing $20 \%$ of the microcapsules showed an important color change toward the red and yellow, according to the CIELAB analysis, when heated between $31{ }^{\circ} \mathrm{C}$ and $37{ }^{\circ} \mathrm{C}$. The color change was then perfectly reversible between $34{ }^{\circ} \mathrm{C}$ and $26{ }^{\circ} \mathrm{C}$. Other workers studied the development of heat sensitive wood, either with microcapsules [78] or not $[79,80]$. A self-healing acrylic coating was prepared by Yan and Peng by encapsulating resin in urea-formaldehyde microcapsules [81]. They found that a loading of $4 \%$ of microcapsules was enough to imbue the coating with good self-healing capacities without affecting its mechanical properties. Similarly, Queant et al. encapsulated organic UV absorbers in calcium carbonate microspheres in order to protect them from degradation [82]. A $2500 \mathrm{~h}$ accelerated weathering test showed that wood coated with a transparent waterborne latex would suffer less color changes when the UV absorbers were encapsulated. Other uses for organic additives in wood coatings during the last five years included the enhancement of their mechanical properties [83] and the reduction of the oxygen inhibition [84].

Nanoparticles of metal oxides and silica as wood coating additives allow the preparation of surfaces with a wide array of functionalities. An interesting method to achieve superhydrophobicity was to modify the nanoparticles with a low surface free energy chemical before their incorporation into the coating [85-88]. The low surface free energy of both the modified nanoparticles and the resin would imbue water repellency, and the nanoparticles brought an appropriate micro-/nanoscale architecture to the coating, joining together the two requirements to achieve superhydrophobicity. Sevda et al. experimented the addition of $\mathrm{SbO}_{3}$ and $\mathrm{TiO}_{2}$ to an intumescent paint [89]. They noted that a loading of $2 \%$ of nanoparticles increased of LOI and greatly decreased the weight loss and smoke generation in comparison to the paint alone. Guo et al. prepared bio-sourced silica particles through the calcination of rice husk [90]. After modification with a silane coupling agent (KH-570), a $\%$ loading of the silica in a waterborne acrylic coating improved the elongation at break (244.72\% to $303.06 \%$ ), tensile strength (32.509 $\mathrm{MPa}$ to $48.673 \mathrm{MPa})$, modulus of elasticity (3.010 MPa to $6.672 \mathrm{MPa})$, and pencil hardness $(1 \mathrm{H}$ to $2 \mathrm{H})$ of the resulting coating. Other workers explored the possibilities of these compounds to improve the resistance of wood to decay fungi [91,92], black-stain fungi [93], and photodegradation [94], as well as to improve its mechanical properties $[95,96]$.

In addition to metallic oxides and silica, inorganic compounds of mineral origin were used as additives to improve the properties of organic wood coatings. Atienza et al. used oyster shell powder to make a thermally stable acrylic coating [97]. Because the shells are made of $95 \%-98 \%$ of incombustible calcium carbonate, the addition of $75 \%$ of oyster shell powder to the coating increased the time of burning of the wood samples from $18.00 \mathrm{~min}$ to $29.67 \mathrm{~min}$. Zeolites were also considered as potential fire retardants in a melamine-ureaformaldehyde resin containing ammonium polyphosphate [98]. Due to their very porous nature, most of the zeolites studied showed an appreciable decrease in $\mathrm{CO}_{2}$ production. The ignition time was also greatly delayed, from $138 \mathrm{~s}$ for the resin containing only ammonium polyphosphate to $279 \mathrm{~s}$ with $3 \mathrm{~A}$ zeolites. Although different zeolites performed the best on the different aspects of fire protection, 3A zeolites were, overall, the most performant. Other compounds studied as fire retardants were graphene [99] and sepiolites [100], which could also be used to make hydrophobic coatings. Kolya and Kang coated various species of hardwood with polyvinyl acetate coatings containing modified graphene oxide [101]. The graphene oxide, which had been reduced with $\mathrm{NaBH}_{4}$ in presence of urotropin and further functionalized with poly (diallyl dimethylammonium chloride), slightly increased the water contact angle of the coating on most wood species, with average angles of $91.5^{\circ}$ and $92.7^{\circ}$ on the radial and cross-sectional face, respectively, as compared to $72.5^{\circ}$ 
and $80.1^{\circ}$ for the polyvinyl acetate coating alone. Similarly, Chen et al. functionalized sepiolite with polysiloxane and mixed them with an epoxy [102]. They found that the hydrophobicity of the coating increased rapidly with higher sepiolite:epoxy ratios, with highly superhydrophobic (water contact angle $=166^{\circ}$ and roll-off angle $=5^{\circ}$ ) at 7:5. The wood surface also exhibited good self-cleaning properties and the ability to separate water and oil.

\subsubsection{Organic-Inorganic Composite Coatings}

An extremely large share of the research into wood coatings, over the last five years, focused on the organic-inorganic composite coatings. This section differs from the additives in organic coatings for a few reasons: 1- the organic and inorganic parts, in this section, are not always blended together, 2- the organic part is often not a resin, and 3- the inorganic part is frequently the main component of the coating. Also, organosilicons are an important element of these coatings.

A method frequently encountered to improve the hydrophobicity of the wood surface, and often reach superhydrophobicity, was to use nanoparticles to form a proper micro/nanoscale architecture and thereafter reduce its surface free energy. For this matter, an organic coating could be used to reach the desired low surface free energy $[103,104]$. A superhydrophobic wood surface was prepared by Lozhechnikova et al. after applying positively charged $\mathrm{ZnO}$ nanoparticles and a negatively charged carnauba wax on Norway spruce through layer-by-layer deposition [105]. Not only did the coating reach a $155^{\circ}$ water contact angle (WCA), but it also displayed higher UV stability and moisture buffering. Lu et al. pretreated rubberwood with IPBC, an organic biocide, before dipping it in polystyrene and $\mathrm{SiO}_{2}$ solutions [106]. At higher $\mathrm{SiO}_{2}$ concentrations (2\%), the WCA was $155.6^{\circ}$ and the antiseptic performances of the IPBC were preserved by the coating, which reduced its leaching. A superhydrophobic coating with a high thermal energy storage capacity was designed by Kong et al. through spraying with mesoporous polydivinylbenzene nanotubes, fluorine-containing $\mathrm{SiO}_{2}$ nanoparticles and paraffin wax [107]. Upon exposition to excessive heat, the wax trapped in the nanotube would melt to store thermal energy and later release this energy through crystallization. This kind of wood surface improvement strategy was also used by other workers to imbue wood photostability [108], molds resistance [109], selfhealing [110], thermal stability [111], and improved adhesion of UV-curing coatings [112].

The hydrophobization of the micro-/nanoscale architecture could also be achieved by replacing the resins with low surface free energy components [113-132]. As a general rule, these coatings showed superhydrophobicity (contact angle $>150^{\circ}$, roll-off angle $<10^{\circ}$ ), high resistance to mechanical wear (abrasion, cutting, etc.), and sometimes properties such as chemical resistance and self-healing. Wang et al. developed an interesting method to grant superhydrophobicity to Chinese fir, where they obtained the desired micro-/nanoscale architecture simply by sanding the wood surfaces with a 240-grit sandpaper [133]. The surface free energy of the produced micro/nanoscale architecture was subsequently reduced by deposition of a fluoroalkylsilane/silica composite suspension to obtain a superhydrophobic surface with good abrasion resistance and self-healing capabilities. Guo et al. created a Mg-Al-layered double-hydroxide coating to improve the fire safety of birch wood via thermal deposition followed by hydrophobization with trimethoxy $(1 \mathrm{H}, 1 \mathrm{H}, 2 \mathrm{H}, 2 \mathrm{H})$ heptadecafluorodecyl)silane [134]. The limiting oxygen index (LOI) of the coated wood increased from $18.9 \%$ to $39.1 \%$, and its total smoke generation and total heat release decreased by $58 \%$ and $40 \%$, respectively. Wang et al. coated poplar wood by dipping in polydopamine for $24 \mathrm{~h}$, electroless $\mathrm{Cu}$ deposition for $12 \mathrm{~h}$, and dipping in octadecylamine for $24 \mathrm{~h} \mathrm{[135].} \mathrm{Although} \mathrm{the} \mathrm{process} \mathrm{was} \mathrm{quite} \mathrm{tedious,} \mathrm{the} \mathrm{resulting}$ coating was extremely durable, keeping its superhydrophobicity even after degradation by UV light, acids, bases, organic solvents (n-hexane, acetone, ethanol, and DMF), and boiling water. Huang et al. modified nanofibrillated cellulose [136] and lignin-coated cellulose nanocrystals $[137,138]$ coated wood with $1 \mathrm{H}, 1 \mathrm{H}, 2 \mathrm{H}, 2 \mathrm{H}$-perfluorooctyltrichlorosilane through chemical vapor deposition. The resulting wood surface showed high sandpaper 
abrasion and UV resistance, as well as superhydrophobic and self-cleaning behaviors. The naturally hydrophobic micro/nanoscale structure of canna leaves [139] and rose petals [140] was re-created by Yang et al. through nanoimprint lithography. They first created a PDMS template of the canna leaves and rose petals, which was use to make a perfect copy of the said structure with $\mathrm{SiO}_{2}$ and polyvinyl butyral. The copy could then be peeled from the template and stuck to the wood surface to reach superhydrophobicity. A similar strategy was used by Chen et al. to create superhydrophobic and magnetic wood surfaces based on the structure of taro leaves with $\mathrm{F}_{3} \mathrm{O}_{4}$ and PDMS [141]. Gan et al. also prepared superhydrophobic wood surfaces with a ferromagnetic behavior by dipping poplar samples in a solution of hydrophobized $\mathrm{CoFe}_{2} \mathrm{O}_{4}$ nanoparticles, which had a contact angle of $158^{\circ}$, high resistance to sandpaper abrasion, and improved microwave absorption properties [142].

Some organic-inorganic composite coatings were prepared simply by adding organic and inorganic moieties together on the wood surface. Wang et al. used tannic acid$\mathrm{Fe}^{3+}$ complexes in combination with silver nanoparticles to create a superhydrophobic coating [143]. The developed coating was highly durable, keeping a contact angle higher than $150^{\circ}$ after $\mathrm{UV}$ exposition and degradation by $\mathrm{HCl}, \mathrm{NaOH}, \mathrm{n}$-hexane, acetone, ethanol, DMF and boiling water. A magnetic wood coating based on chitosan, sodium phytate and nano- $\mathrm{Fe}_{3} \mathrm{O}_{4}$ was prepared by Tang and $\mathrm{Fu}$ through layer-by-layer deposition [144]. They found that paramagnetic wood with narrow and long magnetic hysteresis loops could be created with this method, the magnetic properties of the treated wood being directly related to the number of layers in the coating. Uddin et al. prepared a paste with $\mathrm{Mg}(\mathrm{OH})_{2}$ and casein to improve Scots pine's resistance to fire [145]. The prepared wood surface had a delayed time to ignition (12.1 s to $30.4 \mathrm{~s}$ ), a lower peak heat release $\left(216 \mathrm{~kW} / \mathrm{m}^{2}\right.$ to $\left.119 \mathrm{~kW} / \mathrm{m}^{2}\right)$ and a lower total heat release $\left(79.5 \mathrm{MJ} / \mathrm{m}^{2}\right.$ to $\left.53.3 \mathrm{MJ} / \mathrm{m}^{2}\right)$, as well as decreased smoke production and mass loss. Another fire-retardant coating was prepared by Xie et al. through dipping in different solutions containing graphene oxide and functional cellulose [146]. These coatings scored a V-0 rating in a vertical burning test, FH-1 or FH-2 rating in a horizontal burning test, had a greatly increased LOI, and could self-extinguish when removed from the flame source. In presence of moisture, they could even self-heal incisions with widths up to $320 \mu \mathrm{m}$.

\subsubsection{Inorganic Coatings}

Metallic oxides and silica played an important role in the last five years of research in the domain of wood coatings [147-149]. They were layered on wood surfaces with a variety of methods, including sol-gels [150-152]. Sol-gels with $\mathrm{SiO}_{2}, \mathrm{TiO}_{2}$, and $\mathrm{Fe}^{3+}$ [153] or $\mathrm{Zr}^{4+}$ [154] were used to make photostable wood surfaces with photocatalytic activity, granting them self-cleaning capabilities through the photodecomposition of organic pollutants. Qian et al. also used sol-gels to develop a coating based on microcapsules with $\mathrm{Fe}_{3} \mathrm{O}_{4} / \mathrm{SiO}_{2}$ shell and a phase changing material core to imbue energy storage and magnetism to poplar wood [155]. The hydrothermal growth and deposition of metallic oxides were also the subject of many publications [156-159]. Sun and Song casted $\mathrm{WO}_{3}$ on poplar wood through hydrothermal in situ synthesis [160] or nanosheet deposition [161] to build photochromic wood. The resulting wood surfaces could reversibly change color after exposition to UV radiations, had better photostability and could be hydrophobized with $1 \mathrm{H}, 1 \mathrm{H}, 2 \mathrm{H}, 2 \mathrm{H}$-heptadecafluorodecyl)silane. Similarly, $\mathrm{MoO}_{3}$ was hydrothermally grown or deposited on birch to yield photo-responsive wood with a blue shift when exposed to UV light [162,163]. Wang et al. prepared magnetic wood with fire-retardancy through the hydrothermal deposition of $\mathrm{MnFe}_{2} \mathrm{O}_{4}$ [164]. The initial burning time of the coated wood was delayed from $6 \mathrm{~s}$ to $20 \mathrm{~s}$, its electromagnetic waves absorption capacity was improved, and it could additionally be hydrophobized with fluoroalkylsilanes [165]. A very interesting silica coating was prepared by Belykh et al. by mixing sodium liquid glass and black shale, which are byproducts from the fabrication of ferrosilicon and gold mining activities, respectively [166]. They found that good adhesion could be achieved by using $20 \%-35 \%$ of black shale, while $10 \%-25 \%$ yielded a good reduction of the mass loss 
when exposed to fire. They also found that adding $1 \%$ of a synthetic foaming agent (PO-6) improved both the adhesion and fire resistance of the coating.

Among the other approaches to coat wood with inorganic materials, Pan et al. used an electroless plating method to coat poplar disks with nickel (Ni) [167]. They found that the disks' resistance would decrease from $12 \Omega$ to $1 \Omega$ within the first 5 minutes of electroless plating, that the hydrophobicity of the coated wood slightly increased, and that an electromagnetic shielding effectiveness between $55 \mathrm{Db}$ and $65 \mathrm{Db}$ could be achieved. Similar methods were also studied to coat poplar with $\mathrm{Cu}-\mathrm{Ni}$ [168] and Ni-P [169] composites. A superhydrophobic wood surface was created by Wang et al. by deposing copper on a wood substrate with a vacuum evaporator, followed by the growth of a silver layer through immersion in a $\mathrm{AgNO}_{3}$ solution [170]. The prepared wood surface, which had a contact angle of $160.5^{\circ}$ and a roll-off angle near $0^{\circ}$, could keep its superhydrophobicity after 100 cycles of tape abrasion or $200 \mathrm{~cm}$ of sandpaper abrasion with a $50 \mathrm{~g}$ weight. Hydrophobic wood surfaces were prepared by Łukawski et al. via drop casting and dipping with different solutions of carbon black, graphene, and carbon nanotubes [171]. Concentrations as low as $0.05 \mathrm{~g} / \mathrm{m}^{2}$ of nanomaterials were sufficient to reach very high water contact angles (up to $143^{\circ}$ ), although superhydrophobicity was not achieved. They also found that, while carbon nanomaterials do not make covalent bounds with wood, the coatings' resistance to sandpaper was quite good. Yuan et al. used hydrothermal deposition of graphitic carbon nitride nanosheets to improve the photostability of poplar wood [172]. They found that the nanosheets could absorb $90 \%$ of the UVA and UVB, substantially reducing the color changes after accelerated weathering. Furthermore, TG and DTG showed an improvement of the thermal stability of the coated wood. Another use of inorganic nanosheets as wood coatings was explored by Liu et al. who coated cedar wood with boron nitride nanosheet to improve its performance against fire [173]. The obtained wood surface showed a good thermal stability after $60 \mathrm{~s}$ of exposition to a lighter and an improved resistance to oxidation.

\subsection{Wood Surface Modification}

Instead of improving wood surfaces through the addition of an outer layer, different modification methods allow for the enhancement of the wood's properties directly. These methods involve the chemical modification of the wood surfaces by different means to improve their wettability, decay-fungi resistance, photostability, and more.

\subsubsection{Plasma Modification}

An environmentally-friendly way to modify the surface of wood is through plasma treatments. Plasmas are highly reactive chemical environments with interesting features such as scalability and the absence of solvents [174]. They exist under various forms, which can be thermal or non-thermal [175]. In the case of wood protection, however, non-thermal plasmas are preferred to avoid its thermal degradation. An interesting use of plasmas in wood surface modification is to oxidize its polymeric constituents to increase its surface free energy and wettability. Over the last 5 years, many workers explored this application to increase the interactions between wood and adhesives or coatings [176-187]. They found that using reactive carrier gases such as air and $\mathrm{O}_{2}$ would lead to the creation of polar groups such as carboxyl and carbonyl at the surface of the treated wood, increasing its hydrophilicity and surface free energy. The plasma-treated wood would therefore have much lower contact angles with water and water-based coating solutions, showing an enhanced wettability, as well as a faster and deeper absorption of those liquids. As a result, the adhesion of coatings and adhesives would often be greater on treated wood than on its untreated counterpart.

Žigon et al. [188] and Žigonand Dahle [189] used a floating electrode dielectric barrier discharge (FE-DBD) plasma to treat Norway spruce following a short dip in $\mathrm{NaCl}$ solutions. They found that the electric conductivity and the intensity of the discharge were both increased by the $\mathrm{NaCl}$, which led to an enhanced wetting of the wood following the plasma treatment. As a result, the contact angle with water and a water-based coating were lower 
and the tensile strength of the coating was improved. In another study, Žigon et al. used different adhesives to bind beech to aluminum and steel after treating both the wood and metals with a FE-DBD plasma [180]. The surface free energy of all the substrates increased following the plasma treatment, which led to higher tensile shear strength in most of the studied scenarios. After noting the poor adhesion of a water-based primer to beech veneers and of a water-based topcoat to an oily UV-cured primer, Peng and Zhang treated both the wood veneers and the UV-cured primer with a DBD plasma before laying the subsequent coat [190]. They found that the wettability of the beech veneers and the primer increased following the plasma treatment, which led to a large enhancement of their adhesion. Similarly, Dahle et al. dip-coated pine samples with polystyrene microspheres before proceeding to plasma modification of the coating [191]. As hydroxyl and carbonyl groups were created on the polystyrene layer, the wood surface became superhydrophilic and may eventually be used as a primer for further plasma polymerization. In an effort to improve the fireproofing of wood, Gospodinova and Dineff studied the effect of a plasma treatment on the absorption of fire-retardant solutions [192]. They found a substantial increase in the surface free energy and of the penetration-spreading parameter after the plasma treatment, but also a rapid decrease in these two variables during a post-treatment storage. Finally, Volokitin et al. used a thermal plasma treatment to mimic a thermal treatment on the surface of pine and birch [193]. Similar to typical thermal treatments, the modified samples were darker, their water contact angle increased, and their water absorption declined.

Other uses for plasma treatments in wood-surface protection are the grafting of chemical components and the creation of thin coatings. Due to their highly energetic and reactive nature, plasmas can melt metallic particles or break down organic molecules into reactive moieties while creating radicals on the surface of wood, which allows the growth of thin coating layers or the functionalization of wood surfaces $[194,195]$. Thereby, a $\mathrm{Zn} / \mathrm{ZnO}$ thin coating was deposited on beech wood by Wallenhorst et al. through the cold plasma spraying of $\mathrm{Zn}$ microparticles with air as the process gas [195]. After $50 \mathrm{~h}$ of exposition to UV radiations, the thickest coating almost completely inhibited to color changes $\left(E^{*} \approx 0\right)$, while uncoated wood had a $E^{*}$ of 10 . They also found that the coating could protect a polyurethane topcoat from photodegradation. Similarly, Profili et al. prepared a hydrophobic $\mathrm{ZnO} / \mathrm{SiO}_{2}$ composite coating on sugar maple with a DBD plasma [196]. The coating, formed by the embedding of $\mathrm{ZnO}$ particles in a $\mathrm{SiO}_{2}$ layer, displayed a static water contact angle of $100^{\circ}$, while the untreated samples quickly absorbed the water droplets. A superamphiphobic coating was casted on birch wood by Tuominen et al. by depositing titanium nanoparticles with a liquid flame spray followed by the plasma polymerization of perfluorohexane [197]. The coating, which displayed contact angles $>160^{\circ}$ with water, ethylene glycol, diiodomethane, and olive oil, was also highly resistant as its wetting properties were still intact after a 500,000 water drops impact test. Furthermore, good self-cleaning properties were noted with both water and oil.

The hydrophobization of wood surfaces through plasma treatments with fluoroalkanes and organosilicons also received some attention over the last five years. Notably, de Cademartori et al. created a fluorocarbon film on white spruce and Brazilian cedar by polymerizing octofluoropropane with a DBD plasma [198]. They found that longer treatment periods would lead to higher hydrophobicity, with optimal water contact angles of $135.2^{\circ}$ and $129.8^{\circ}$ on the spruce and cedar, respectively. Levasseur et al. also used $\mathrm{C}_{3} \mathrm{~F}_{8}$ to improve the hydrophobicity of sugar maple wood by DBD plasma with inert gases (Ar and $\mathrm{N}_{2}$ ) [199]. They noted that the hydrophobicity of the obtained surfaces was directly linked to the voltage of the plasma, which could yield a $140^{\circ}$ static water contact angle at the highest voltage $(10 \mathrm{kV})$. After letting the coating age for 125 days under uncontrolled conditions, the wetting properties of the wood surface remained unchanged. The possibility to increase or decrease the wettability of wood through cold remote $\left(\mathrm{N}_{2}+\mathrm{O}_{2}\right)$ plasma was studied by Bigan and Mutel [200]. They noted that the water absorption of different plasma-treated wood species could significantly increase (up to 5.5 timesin the case of 
beech) by using the plasma treatment alone, but that adding 1,1,3,3-tetramethyldisiloxane could make the wood superhydrophobic. Wood coatings with both hydrophobicity and good thermal stability were prepared by Sohbatzadeh et al. [201] and Chen et al. [194,202] through the plasma polymerization of hexamethyldisiloxane. Wood surfaces with lower surface free energy and increased roughness were obtained, yielding water contact angles as high as $138^{\circ}$. Many other studies were conducted over the last five years to improve the properties of wood surface through plasma treatments, including polyester powder [203], polyester with aluminium coated silver and bismuth oxide [204] or $\mathrm{TiO}_{2}$ [205], copper and aluminium microparticles with an acrylic binder [206], $\mathrm{ZnO}$ [207], $\mathrm{TiO}_{2}$ [208], and various biocidal precursors [209].

\subsubsection{Other Surface Modification Methods}

Beside plasma treatments, many methods were used, over the last years, to improve the properties of wood surfaces through modification. Herein, those methods are classified into two categories: chemical methods and carbonization methods. The chemical methods relied on chemical reactions or interactions to tone the properties of the outmost surface of the treated wood; a slight penetration of the chemicals into the wood was considered a surface impregnation, which will be reviewed in the next section. The chemical grafting of chemicals on the surface of wood involves the creation of a covalent bond between the wood cell wall and the modifying agent. This method allows to improve the surface properties of wood while reducing the leaching of the chemicals [210]. Wang et al. grafted poly(2- (perfluorooctyl)ethyl methacrylate) on the surface of Chinese fir by atom transfer radical polymerization [211]. The modified wood had a strong superhydrophobic behavior, which was only slightly affected by finger-wiping and tape-adhesion abrasion tests. Furthermore, the treated wood showed excellent resistance to the mold Aspergillus niger and self-cleaning properties. A similar method was used by Sharma et al. to graft acetonitrile and ethyl acrylate on pine wood [212]. Under optimal conditions, they obtained a percentage grafting of $85.34 \%$, which greatly reduced the swelling of the treated wood in different solvents and solutions, as well as its weight loss when dipped in strong bases and acids. An environmentally-friendly treated was developed by Filgueira et al. as they grafted modified Pinus radiata tannins and condensed tannins on beech wood through the action of a laccase enzyme [213]. They found that treating wood this way, under an alkaline medium $(\mathrm{pH}=10)$, would reduce its water absorption over $72 \mathrm{~h}$ by $20 \%$ and reduce the leaching of the treatment by $76 \%$. Song et al. modified the surface of balsa wood by dipping samples for $60 \mathrm{~s}$ in aqueous solutions containing $0.75 \%$ of different salts [214]. They found that the metal ions, particularly $\mathrm{Zr}^{4+}$, could attain a water contact angle up to $145^{\circ}$ through the creation of a microstructure and crosslinking. However, the durability of such treatment seems rather low, as the contact angle dropped to $138^{\circ}$ after 14 days ambient conditions. The fluorination of silver fir and Douglas fir with gaseous $F_{2}$ was studied by Pouzet et al. $[215,216]$. They found that the treatment would substitute hydroxyl groups from the cell wall polymers for fluorine, reducing the surface free energy of the treated wood. As a result, the water contact angle increased up to $120^{\circ}$, the water absorption decreased drastically, and the treatment was still as hydrophobic two years later. However, while short treatment times had only a low effect on the integrity and color of the treated wood, treatments of $20 \mathrm{~min}$ led to a severe degradation of the tracheids and browning of the wood surfaces. In another study, they also noted that a torrefaction post-treatment would help to purge the HF produced by the reaction of $\mathrm{F}_{2}$ with wood and further slow down the ingress of water without causing any defluorination of the treated wood [217]. The combination of a laccase enzyme surface treatment and pressure impregnation of copper(II) sulfate pentahydrate was explored by Gabrič et al. [218]. They found that a laccase pre-treatment would make the cell walls of the wood swell, preventing its impregnation; however, using the laccase as a post-treatment would greatly reduce the leaching of the copper. Furthermore, the laccase treatment alone could reduce the mass loss due to the degradation by brown- and white-rot fungi by roughly a third. More chemicals were studied over the course of the last 
five years to modify the surface of wood, including aminoborates [219], methanol [220], cellulase [221,222], poly(methylhydrogen)siloxane [223], and chitosan [224].

As the name implies, the carbonization methods revolve around charring the surface of wood to modify its properties. The use of $\mathrm{CO}_{2}$ lasers with radiation doses up to $75 \mathrm{~J} / \mathrm{cm}^{2}$ was studied in several publications, as well as its effect on the tensile strength of adhesives, the resistance to molds of the treated wood and its surface free energy [225-227]. The authors found that high radiation doses would increase the wood surface blackening, as a result of the carbonization, as well as its resistance to molds. However, they noted that the treatment was only effective against Aspergillus niger. Studies of the surface properties showed that the loss of hydroxyl groups reduced the surface free energy of the treated wood, which decreased the tensile strength of polyurethane and polyvinyl acetate adhesives. Other authors explored the carbonization of wood by pressing a single surface of the treated wood with a hot metal plate at different temperatures $\left(220{ }^{\circ} \mathrm{C}\right.$ to $\left.400{ }^{\circ} \mathrm{C}\right)$ for different periods (30 s to $2 \mathrm{~h}$ ) [228-230]. They observed highly modified moisturerelated behaviors, with higher water contact angles, lower water absorption, and lower equilibrium moisture contents (EMC). As a result of the reduced EMC, the modulus of rupture of the charred wood was also slightly higher. A similar study was conducted by Akçay et al., wherein, pine and beech surfaces were carbonized with a blow torch to improve the wood's resistance to white- and brown-rot fungi [231].

\subsection{Wood Surface Impregnation}

The properties of the wood surfaces can be improved with a shallow impregnation of chemicals. It can be achieved by different means, from brushing and very short dippings (few seconds) to longer dippings (few hours) and single face vacuum impregnation. Very few publications on the subject of impregnation presented details about the impregnation depth of the chemicals or their distribution into the wood; consequently, different parameters were taken into consideration to decide if a method would be considered as a surface impregnation: the use or not of pressure/vacuum, the duration of the treatment, the size of the samples, whether the samples were completely or partially covered by the treatment, and the weight gain. Petrič described surface impregnation as the impregnation of the first few millimeters of the cross-section of wood [175]. While this definition was used as the basis to classify the treatments as surface impregnation, it seemed rather ambiguous, as some hard-to-treat species can only be treated by a few millimeters in the cross-section, even with a vacuum/pressure process. Accordingly, treatments that would allow high longitudinal penetration were also rejected.

A primary way to treat wood by surface impregnation was through the insertion reactive material. Triquet et al. chemically increased the surface density of various hardwood species by in situ polymerization of acrylate monomers [232]. The monomers were vacuum impregnated for $150 \mathrm{~s}$ after being dropped on a single surface of wood, which was followed by electron-beam polymerization. The density of the treated wood increased by nearly $200 \mathrm{~kg} / \mathrm{m}^{3}$ near the surface, which lead to an augmentation of the Brinell hardness. Different workers studied the possibility of reducing the set-recovery of unilaterally compressed wood with the impregnation of chemical agents. While the compression of wood itself is not a subject of this review, the effect of a surface pre-treatment on its durability was deemed appropriate. Wu et al. impregnated poplar wood with a reactive waterborne acrylic resin by immerging a quarter of the wood blocks into the resin solution and applying a vacuum, leading to weight percent gains ranging from $1.1 \%$ to $4.7 \%$ [233]. Afterward, the impregnated surface was densified with a hot press under different temperatures ranging from $150{ }^{\circ} \mathrm{C}$ to $180^{\circ} \mathrm{C}$. At the highest loading of resin, the set-recovery of the impregnated wood was only $1.8 \%$, while the control samples reached $73.0 \%$. Similarly, Han partially soaked Scots pine for different durations in a furfuryl alcohol solution containing a maleic anhydride catalyst before pressing a single surface with a hot metal plate [234]. Under optimized conditions, the set-recovery of the densified wood decreased from $60 \%$ to $14 \%$. Various impregnation agents were studied by Neyses et al. to achieve the same goal, 
although the results were not as satisfying [235]. Lafond et al. improved the embedment capacity of black spruce connectors through the impregnation of acrylates [236]. They found that a chemical retention of $7 \%$ could improve the bearing strength of the connector by $48 \%$ and their stiffness by $27 \%$. Finally, the development of colored wood surfaces through the creation of complexes between phenolic extractives and metal ions was explored by Dagher et al. [237]. After simply applying a 1\% ferric sulfate solution on the surface of different hardwoods with a foam roller applicator, different colors were developed for each species according to their phenolic extractives content.

Another way to protect wood by surface impregnation is to simply insert protective agents slightly under its surface. Harandi et al. brushed $5 \%$ and $10 \%$ solutions of poly(vinyl butyral-co-vinyl alcohol-co-vinyl acetate) (PVBVA) on silver fir to improve its mechanical properties [238]. They found that both solutions increased the water contact angle to $90 \%$, reaching hydrophobicity, and improved the modulus of rupture (MOR), modulus of elasticity (MOE), plastic hardness and Martens hardness of the treated specimens. Although the more viscous $10 \%$ solution took more time to be absorb, it yielded equivalent MOR and MOE, as well as higher plastic hardness and Martens hardness than the $5 \%$ solution. Kumar et al. dipped Norway spruce blocks in a $1 \%$ solution of octadecyltrichlorosilane for $30 \mathrm{~min}$ to $120 \mathrm{~min}$, yielding from $0.7 \%$ to $2.4 \%$ weight percentage gains $[239,240]$. They found that the treated specimens had very high static water contact angles $\left(140-150^{\circ}\right)$, a negligible water absorption through immersion, a lowered equilibrium moisture content when exposed to a high relative humidity (95\%), an increased dimensional stability, and a reduced mass loss when exposed to the brown-rot fungi Coniophora puteana. The impregnation of poplar wood with $\mathrm{K}_{2} \mathrm{CO}_{3}$ and $\mathrm{SiO}_{2}$ solutions to improve its fire-retardancy was studied by He et al. [241]. They found that the limiting oxygen index (LOI) increased from $20.5 \%$ to $33.5 \%$ prior to the treatment, and only decreased to $30.5 \%$ after leaching. Thermogravimetric measurements showed that the mass loss decreased during the charring phase $(63.2 \%$ to $47.4 \%)$ and the calcining stage (34.8\% to $24.3 \%)$, while the char generation increased. Thermochromic wood veneers were prepared by Zhu et al. through the ultrasonic impregnation of a thermochromic dye and a color developer [242]. The treated wood, which was very dark, could return to its original color between $28^{\circ} \mathrm{C}$ and $38^{\circ} \mathrm{C}$, while the discoloration was reversible between $34{ }^{\circ} \mathrm{C}$ and $22{ }^{\circ} \mathrm{C}$. Other publications reported the surface impregnation of chemicals to decrease the wettability [57], flammability [243], mold [244,245] and mildew [246] degradation, and dimensional instability [247] of various wood substrates.

\section{Discussion}

As previously presented, a very wide variety of methods can be used to protect the surface of wood, combining various techniques and chemicals. However, in order to have a concrete beneficial effect on our lives, new wood protection innovations must be used in real buildings. The use of wood in construction is however a fairly specific domain, where the application determines which properties (photostability, hydrophobicity, fireretardancy, self-cleaning etc.) are needed and which sources of wear and degradation can be encountered. Different considerations must be taken into account, such as governmental regulations or the treatment's cost, duration, durability, and ecologic footprint. This section of the review will be dedicated to discussing some of these specificities to identify which trends and treatments could be adequate in different situations.

\subsection{Normative Aspects}

A first prerequisite for any technology to be applied in real-life applications is to satisfy different local norms and regulations. As an aegis of the public's safety, these regulations emphasize the need for wood-based products to be performant and legitimize the development of new and innovative treatments. Different aspects of wood protection are supervised by authorities, such as fire safety and decay. 
Fire hazards present a huge stake in lumber construction, particularly for highreaching buildings ${ }^{26}$. They often compel construction companies to hide the wood behind noncombustible material, restricting the use of apparent timber. Specific guidelines dictate the way wood buildings must be constructed and important restrictions are applied to ensure the safety of the construction workers and the residents [248]. They include criteria, such as the charring rate and the preservation of the load-bearing capacity of the building in the event of a fire. In order to reach these targets, wood surface modifications can become key elements to create high quality materials. Satisfyingly, many workers over the last five years tackled the challenge of improving the fire safety of wood through surface improvements. In fact, almost every trend presented in this review contained at least one treatment aimed at reducing the hazards of flames.

Organic coatings were particularly studied for this subject, either by the inclusion of phosphorous reactives [30-35] or additives [63,85,89,97-100]. Different mechanisms were tested to promote the fire safety of wood such as an increased char formation, a delayed time to ignition, an increased limiting of the oxygen index (LOI), and a lower smoke release. Phosphorous reactives were usually quite effective at increasing the char formation and the LOI. The formation of char at the surface of wood is an excellent mechanism to improve its fire safety, as it creates an insulating layer that protects its inner section and decelerates the loss of mechanical properties [249]. This kind of protection is actually very interesting as a category of fire-retardant coatings; the intumescent coatings were designed to utilize this mechanism to protect wood from flame sources by transforming into a porous insulating char barrier upon heating [250]. The LOI is also an important aspect of fire protection; as an indicator of the flammability of a material, it indicates how readily the substrate will ignite and extinguish [251]. A LOI as high as 33\% was obtained by Lokhande et al., while removing the phosphorous moieties from the coating would reduce this value to $23 \%$ [34]. As a whole, it shows that phosphorous reactives offer great potential for producing fireproof coatings.

Organic coating additives were very efficient at reducing the aspects related to the combustion of the wooden substrate such as the ignition time, the burning time, and the heat release. Although many different chemicals were used as additives to increase the thermal stability of the coatings, they presented similar properties as they had a mineral nature in common. As such, they displayed low flammability, reactivity with oxygen, and thermal conductivity, resulting in a less intense combustion. An interesting coating was developed by $\mathrm{Wu}$ et al. through the addition of zeolites in a melamine-urea-formaldehyde resin containing ammonium polyphosphate [98]. As very porous material with high surface area, zeolites can adsorb high quantities of gases; by using the right zeolites, the release rate of $\mathrm{CO}$ and $\mathrm{CO}_{2}$ could be decreased.

Other approaches were investigated to improve the thermal stability of wood surfaces. Among those, inorganic coatings were extensively studied, particularly through hydrothermal deposition $[122,164,172,173]$. Their impact on the combustibility of wood was similar to that of organic coating additives, as their chemical nature and properties are similar. Accordingly, higher LOI, delayed ignition and lower mass loss could be achieved with these simple treatments. High thermal stability was also achieved with surface impregnation of chemicals [241,243], which is perfectly coherent since pressure impregnation of fireretardant compounds is conventional in wood protection. However, many issues can be encountered with fire-retardant pressure impregnated wood such as high chemical uptake and leaching, moisture sensitivity, and reduced mechanical strength $[250,252]$. Thereby, the methods focusing on the surface impregnation did not only simplify the treatment procedures, but they also showed good performances at a lower product retention. Moreover, the combination of silica and $\mathrm{K}_{2} \mathrm{CO}_{3}$ presented by He et al. displayed a fairly lower leaching when compared to the $\mathrm{K}_{2} \mathrm{CO}_{3}$ alone [241].

Another crucial aspect of wood protection is the use category. The need for protection of timber is directly related to the source of degradation it is exposed to; accordingly, regulations exist to ensure that wood exposed to certain elements, particularly wood eating 
organisms, will be able to withstand the degradation. An example of such classification was prepared by the American Wood Protection Association (AWPA) with uses categories such as "interior dry" (UC1), "exterior above ground, coated with rapid water runoff" (UC3A), "ground contact, general use" (UC4A), and "Marine Use, Northern Waters (Salt or Brackish Water)" (UC5A) [253]. While using natural resistant species can help to attain satisfying levels of resistance, using proper treatments allows for reaching higher-use categories with cheaper and abundant species.

As a biomaterial mostly composed of carbohydrates, wood can be consumed by different living organisms such as molds, decay fungi, insects, and marine borers, which leads to various complications [5]. While molds feed on small molecules contained in the parenchyma such as fatty acids and starches, leaving the polymeric constituents intact, they create unsightly discolorations on the surface of the wood [4]. While this aspect does not represent a threat to human health, it does reduce the lifespan of timber, which is of ecological and economical importance. Moreover, they also release spores into the air, which represents an important health hazard. Decay fungi, on the other hand, do feed on the structural polymers of wood, creating not only a discoloration of the surface of wood, but also mechanical damage [254]. As a result, the chemical properties of the timber are modified, and its mechanical strength is greatly impaired. In order for molds and decay fungi to grow, different conditions must be met. The most important one is having a sufficient amount of moisture in the wood, which can be as low $12.3 \%$ of the dry mass of wood depending on the fungus [255]. Additionally, moisture changes in wood are linked to dimensional variations, which are directly responsible for mechanical defects like cupping and cracking [256]. While wood used indoor is rarely subjected to such a high moisture content, it is a different reality when it comes to wood exposed outdoor.

The significance of this issue can easily be visualized by the huge number of publications targeted at increasing the hydrophobicity of the wood surfaces over the last five years. Because the exposure to rain represents such an abundant source of water for wood to absorb, a lot of treatments were prepared to imbue wood surfaces with (super)hydrophobicity. The most prominent trend surrounding the hydrophobization of wood was through the deposition of inorganic nanoparticles, either before or after modification with low surface free energy compounds. In order to achieve superhydrophobicity, both a high water contact angle $\left(>150^{\circ}\right)$ and a low roll-off angle $\left(<10^{\circ}\right)$ are required [20]. An effective method to obtain very high contact angles is to create a surface with variations at a microscopic scale covered with nanosized indentations (micro-/nanoscale architecture) [257]. This structure can easily be achieved with nanoparticles, although a very innovative approach was developed by Wang et al. to prepare this architecture simply by sanding the wood substrate with a 240-grit sandpaper [133]. For water to easily roll over the surface, its surface free energy should be as low as possible to minimize its interactions with water. The most frequent compounds studied to decrease the surface energy of the wood surfaces were fluorinated moieties and organosilicons, but could also include organic resins, waxes, or organic acids [88,131].

The large quantity of superhydrophobic coatings developed over the last 5 years showed the importance to protect wood from water, but also that it is a well-understood subject. Consequently, attention should be given to coatings that could combine superhydrophobicity with other important properties. As a result of their precise micro-/nanoscale architectures, superhydrophobic coatings tend to be fragile and lose their superhydrophobicity once subjected to mechanical wear [258]. Many workers studied the effect of sandpaper abrasion on the hydrophobicity of their coatings, which almost always resulted in a consequent decrease in the water contact angle. However, some coatings did perform quite well when exposed to sandpaper abrasion [118,123,136-138], showing that superhydrophobicity can be combined with durability. In addition to high-wear resistance, the longevity of different superhydrophobic coatings were further improved through selfhealing $[110,133]$, which allows to recover the micro-/nanoscale architecture following mild physical damage. Other elements of the protection of wood were also incorporated to 
superhydrophobic coatings including photostability $[105,205,207,208]$, resistance to chemicals [88], and thermal stability [85,111]. Beside aspects related to the preservation of timber, some publications described superhydrophobic coatings with interesting new functionalities. Kong et al. spray coated a solution containing a paraffin wax, polydivinylbenzene nanotubes, and fluorine-containing $\mathrm{SiO}_{2}$ nanoparticules on a wood substrate [107]. In addition to its superhydrophobicity, the wax absorbed in the nanotubes could act as an energy storage when exposed to high temperatures, absorbing excessive heat through fusion; the heat could later be released as the wax would crystalize. Poplar wood with a ferromagnetic behavior was prepared by Gan et al. after applying a layer of epoxy primer and dipping it in a solution of $\mathrm{CoFe}_{2} \mathrm{O}_{4}$ nanoparticles hydrophobized with $1 \mathrm{H}, 1 \mathrm{H}, 2 \mathrm{H}, 2 \mathrm{H}-$ perfluorodecyltriethoxysilane [142]. Beside a high water contact angle and resistance to sandpaper abrasion, the prepared wood surface had significantly improved microwaves absorption properties and a minimum reflection loss of $-12.3 \mathrm{~dB}$.

While rain represents an important aspect of the protection of wood against water, it is possible for wood to reach a sufficient moisture content to promote the growth of molds and decay fungi simply from the air moisture. Consequently, even wood sheltered from the rain may reach a critical water content without proper protection. Sadly, very few treatments presented in this review could decrease the absorption of moisture, or at least very few were tested for this application. Qu et al. dip-coated Chinese fir in different solgels made from tetraethoxysilane (TEOS) and methyltriethoxysilane (MTES) [150]. After $30 \mathrm{~d}$ of conditioning at $90 \%$ relative humidity and $30^{\circ} \mathrm{C}$, the resulting coatings absorbed much less moisture than their uncoated counterparts, with mass gains reduced from more than $10 \%$ to $1 \%$. Another coating was developed by Lozhechnikova et al. through the layer-by-layer application of carnauba wax and $\mathrm{ZnO}$ nanoparticles on Norway spruce [105]. They found that a single bilayer would suffice to increase the moisture buffer value from 1.12 (untreated spruce) to 1.46 , without any gain when adding more layers. Pouzet et al. decreased the equilibrium moisture content of silver fir and Douglas fir by fluorinating their surface with $\mathrm{F}_{2}$ [216]. After exposing the treated wood to either $30 \%$ or $60 \% \mathrm{RH}$ at $30{ }^{\circ} \mathrm{C}$, they found that the EMC could be up to $20 \%$ lower than the untreated specimens. Finally, the surface impregnation of octadecyltrichlorosilane (OTS) in Norway spruce was studied by Kumar et al. to improve both its hydrophobicity and resistance to brown rots $[239,240]$. They found that the OTS could decrease both the absorption rate of moisture and the equilibrium moisture content of the treated wood, while decreasing the mass loss from the brown-rot fungi Coniophora puteana from $48 \%$ to $15 \%$. As a crucial aspect of the hydrophobization of wood exposed outdoor, the authors believe that more studies should consider including the sorption of moisture in the future.

Of course, when wood cannot be efficiently protected from molds and fungal growth, another option is to treat it directly with biocidal material. Many of the trends presented in this review applied such treatments, including organic coatings [92], organic coating additives, surface carbonization $[225,226]$, and chemical surface modification. Organic coatings containing bio-based materials were presented by many authors, including an antiseptic UV-cured coating made of citric acid and glycidyl methacrylate [43] and a composite coating based on a castor oil maleic anhydride adduct, epoxidized vegetable oil et 5-Bromosalicylic acid [55]. Lazim et al. presented noteworthy coatings prepared with Dioscorea hispida sp. starch and polyvinyl alcohol [41] or polyacrylamide [42] to reduce the degradation of timber exposed to the white-rot fungi $G$. trabeum and C. versicolor. Interestingly, the coatings could reduce the mass loss after 120 days of exposition to the fungi by more than $75 \%$ despite being based on carbohydrates themselves. Because of the harsh conditions and marine borers, the protection of wood in marine environments (Class 5) is extremely difficult and usually relies on the pressure impregnation of toxic chemicals or whole wood modification, or wood is usually destroyed within a year $[259,260]$. Nonetheless, Esfandiar et al. were able to develop a coating that could resist satisfyingly in sea water, reduce the photodegradation of the underlying timber, and reduce the degradation of wood by the barnacles [53]. While their method was extremely tedious ( $24 \mathrm{~h}$ immersion 
in polydopamine, followed by $14 \mathrm{~d}$ in hydroxyapatite, and $4 \mathrm{~h}$ in chitosan), it opens the way for a new generation of seawater-resistant coatings.

Among the additives studied to prevent biodegradation, Ag nanoparticles proved to be efficient against black-stain fungi [93] and bacteria [69]. In their study on the potency of $\mathrm{Ag}$ nanoparticles in acrylic latexes against different black-stain fungi, Boivin et al. noted that a concentration as low as $0.03 \%$ was sufficient to completely inhibit the staining by S. pityophila and E. nigrum, while higher concentration would compromise their dispersion in the film, showing how little of this ingredient could potentially be sufficient. Conversely, Cheng et al. found that much higher doses of Ag nanoparticles were needed in waterborne polyurethane coatings to provide a satisfying antimicrobial activity, although a good synergy was found with nanocrystalline cellulose [69]. As concerns exist around the use of metallic nanoparticles, a more environmentally-friendly method was proposed by Yan et al. to use wheat-straw powder et calcined wheat-straw powder after lignin removal as an antimould agent [76].

A major problem with wood protection is the loss of the chemicals, either through mechanical damages or leaching. Even when wood is satisfyingly protected against biodegradation following the treatment, exposure to the elements can deplete the treatment and make it useless after a while. Some good technologies were developed in the last few years to reduce this problem such as the surface modification of wood, and more precisely the chemical grafting. Wang et al. chemically grafted poly(2-(perfluorooctyl)ethyl methacrylate on Chinese fir by atom transfer radical polymerization [211]. As a result, the treated wood displayed superhydrophobicity, self-cleaning, resistance to A. niger, and extremely high durability to different forms of abrasion. A similar strategy was employed by Sharma et al. to graft acetonitrile and ethyl acrylate on pine samples to improve their antiseptic properties [212]. Additionally, the chemical grafting of hydroxypropylated Pinus radiata bark tannins with laccase enzyme allowed Filgueira et al. to reduce the leaching of the tannins by more than $40 \%$ in acid, neutral and alkaline mediums [213].

Other methods were studied over the last five years to limit the loss of protecting agents. Lu et al. showed that using a coating could contribute to the reduction of the leaching of impregnated material [106]. Indeed, by dipping rubberwood pretreated with 3-iodo-2-propyl-butyl carbamate (IPBC) in polystyrene and silica, they found that the efficiency of IPBC would increase as it cannot leach from the samples and allow the penetration of molds. Pantano et al. added copper-amine, a typical wood preservation agent, as an additive in an acrylic paint [91]. While they found that the leaching of copperamine in the coating was almost 100-fold lower than the impregnated samples, decay tests, however, indicated that it could not properly protect wood from decay fungi. Nonetheless, coatings are not always needed to reduce the leaching of impregnated material, as Gabric et al. found that treating wood with a laccase enzyme could induce the swelling of the cell walls, thereby preventing the chemicals from escaping [218].

As presented in this section, the major risks associated with wood are related to its inherent combustibility and biodegradability. Therefore, from a normative point of view, an ideal treatment could protect wood from both fire and biodegradation. However, none of the treatments presented in this review could achieve both directly. However, some of them could improve the fire safety as well as greatly reduce the absorption of water, which can help to prevent the growth on molds and decay fungi $[85,111]$. Guo et al. prepared a Mg-Al-layered double-hydroxide inorganic coating on birch wood through a hydrothermal process [134]. The resulting wood surface had a greatly increased LOI (from $18.9 \%$ to $39.1 \%$ ), as well as lessened total smoke $(58 \%)$ and heat $(40 \%)$ releases. Thereafter, the coating could be modified with trimethoxy $(1 \mathrm{H}, 1 \mathrm{H}, 2 \mathrm{H}, 2 \mathrm{H}$-heptadecafluorodecyl)silane to reach superhydrophobicity. While the water contact angle on the $\mathrm{Mg}$-Al coated wood was around $50^{\circ}$ and decreasing over time, it was stable at more than $150^{\circ}$ after modification, showing low water absorption. However, the study did not mention if the coating could efficiently protect wood from air moisture. Similarly, Kong et al. developed a superhydrophobic coating with high thermal stability by growing $\mathrm{ZnO}$ nanorods on Chinese fir through an 
hydrothermal process followed by hydrophobization with stearic acid [122]. Furthermore, this coating also displayed a higher photostability, which is crucial for clear coatings used outdoor. Finally, Sohbatzadeh et al. used an atmospheric pressure dielectric barrier discharge plasma to create a rougher surface on fir wood, while depositing a PDMS-like coating with hexamethyldisiloxane as a precursor [201]. The resulting coating increased the water contact angle of the superhydrophilic fir from $0^{\circ}$ to $138^{\circ}$, while retarding the apparition of flames and decreasing its thermal decomposition from $0.94 \mathrm{mg} / \mathrm{min}$ to $0.65 \mathrm{mg} / \mathrm{min}$.

\subsection{Ecological Aspects}

Another prerequisite for applying wood surface treatments at a large scale lies in their environmental footprint. As the awareness of the protection of human health and the ecosystems is on the rise, there is a need for wood treatments to be continuously safer. A first step in this direction is the substitution of solvent-borne coatings and treatments with waterborne alternatives. Indeed, the volatile organic compounds (VOCs) contained in solvent-borne coatings have different consequences on the health of both humans, particularly for individuals with respiratory problems or high sensitivity to chemicals, and the environment [261]. This consideration can be regarded as a success, since only a few of the treatments presented in this review used organic solvents. On the contrary, waterborne coatings were extremely prominent, even though some additives or resins needed to be modified to improve their hydrosolubility.

A typical limitation of waterborne organic coatings, in comparison to their solventborne counterpart, is their high permeability to water. However, many coatings developed during the last few years could overcome this issue. For example, inorganic coatings relying on hydrothermal deposition do not require their precursors to possess a good affinity with water, as they can be deposited from a dispersion or grown from a redox reaction. Consequently, their permeability to water is highly reduced, even more so if they are subsequently modified with a low surface free energy compound. The deposition of highly hydrophobic coatings could also be achieved by plasma polymerization, where neither water nor organic solvents were needed.

Similar to plasma polymerization, many surface improvements could be achieved without a dispersant. The fluorination of wood surfaces achieved a greatly delayed absorption of water [215,216], particularly when combined with a short torrefaction [217]. Pouzet et al. found that reacting wood with gaseous $\mathrm{F}_{2}$ for five minutes could substitute hydrophilic hydroxyls (-OH) for hydrophobic fluorines (-F), which increased the water contact angle on the modified wood, delayed its water absorption, and lowered its equilibrium moisture content. Moreover, the hydrophobicity of the so-treated timber barely decreased after two years. However, this method also involves the generation of HF as a by-product, which undermines the safety aspect. Methods relying on the carbonization of wood like $\mathrm{CO}_{2}$ laser irradiation [225-227], one-sided charring [228-230] and blow-torch combustion [231] improved the resistance to biodegradation and the water sorption properties of the treated wood, although its appearance was notably affected (blackened) by the charring.

Another aspect of the safety of wood surface improvement is the leaching of the chemicals. A lot of the treatments presented in this review rely on silica, metal, and metal oxide nanoparticles, as well as other nano-sized materials. However, there is considerable concern about the release of these compounds since they can represent health hazards for both humans and the environment [262-264]. Additionally, they are expected to stay in the environment for a very long period as they are not readily biodegrade. The toxicity of nanometric compounds is quite complex, depending on many factors such as their ionic strength, size, surface properties, and aggregation. Moreover, they can react with their environment (soil components, moisture, acidity, etc.), which will change their properties, toxicity and mobility [265]. Nonetheless, nanoparticles can enter through the cell wall of mammalian cells and generate cytotoxic reactive oxygen species (ROS) responsible for DNA damages [266-268]. They were also found accumulated in various organs such as the lungs, 
alimentary tract, liver, heart, spleen, and kidneys [269,270]. Adverse effects of nanomaterials were also noted in fish, where they could damage different tissues, create hormonal alterations and even become lethal at fairly low concentrations [271,272]. Although some benefits were observed in plants upon exposure to nanoparticles, different authors also noticed that they could affect the germination of seeds and the growth of the plants, as well as their quality and yield. Furthermore, their hormonal balances were disrupted and some stages such as the flowering and the fruiting could be delayed [273,274]. Fortuitously, many workers used bio-based nanomaterials to obtain similar properties with biodegradable compounds. Different cellulose nanomaterials were used as additives in coatings (film-forming or oils) to improve their mechanical properties; while nanocellulose is not completely safe either, its effect on health is far inferior, and it is readily biodegradable, unless it underwent too much modification [275-277]. As a result, bio-based systems with very high adhesion, hardness, tensile strength and resistance to wear were obtained [59,60,62,64,66-69]. Veigel et al. added nanofibrillated cellulose to linseed oil to improve its mechanical durability [65]. They found that the unmodified oil would quickly become less hydrophobic when exposed to abrasion, while the nanocellulose allowed it to repel water for a much longer time. Also, superhydrophobic coating was prepared by Huang et al. by spraying a nanofibrillated cellulose dispersion on wood specimens before its modification with $1 \mathrm{H}, 1 \mathrm{H}, 2 \mathrm{H}, 2 \mathrm{H}$-perfluorooctyltrichlorosilane [136]. In so doing, they created a wood surface with a $161^{\circ}$ water contact angle, a roll-off angle $<10^{\circ}$, self-cleaning, and extremely high durability, mimicking the typical protocol to obtain superhydrophobic coatings made with inorganic nanoparticles. Similarly, great photostability was obtained by substituting UV absorbers like $\mathrm{ZnO}$ and $\mathrm{TiO}_{2}$ for wood extractives $[70,71,73,74]$. Grigsby added condensed tannins and modified tannins to acrylic coatings to compare their UV blocking capabilities to commercial hindered amine light stabilizers and phenolic stabilizers, finding that $0.5 \%$ of tannins could extend the coatings' life for longer than the commercial options [72]. A multifunctional coating was prepared by Huang et al. by adding cellulose nanofibrils with high lignin content along to western red cedar and lodgepole pine bark extracts in a water-based acrylic [75]. The coating they obtained showed both very good mechanical properties and less photodegradation when exposed to artificial aging.

In a more general fashion, many workers developed wood surface treatments containing bio-based materials over the last five years. These treatments, mostly belonging to the organic coatings' trends, included bio-based monomers for film-forming coatings [41-44,47], modified vegetal oils $[39,40,45,46,51,55,56]$, biological polymers (chitosans, lignin, etc.) $[57,58,92]$, and more $[52,53,76,90,143-145]$. Many advantages come along with these materials, from the cradle to the grave. In general, the activities to generate the raw materials for bio-based components are less energy intensive than their petroleum counterparts, which reduces the consumption of energy and unrenewable resources, as well as the production of greenhouse gases [278-281]. Since they originate from cleaner sources, they also produce less air pollution and they are safer for human health, the ozone layer and ecosystems. Conversely, bad decisions while managing crops destined to become bio-based chemicals can tarnish their health and ecological profiles [278]. The cultivation of plants destined for bio-refining is directly linked to massive land and fertilizer usage, the latter being responsible for eutrophication of surrounding water bodies. This drawback may, nonetheless, be avoided by promoting the valorization of wastes and residues from agricultural and forestry activities, when possible, which would diminish both the pollution and land use associated with the production of crops [282]. Bio-based materials also offer great opportunities in terms of eco-friendly disposal, as they are readily biodegradable just like wood $[283,284]$. Therefore, compostability may be regarded as an acceptable way to dispose of wood coated with bio-based coatings after its useful life. Additionally, bio-based materials are easier to incinerate than synthetic materials, consequently diminishing the recourse to landfilling [285]. The incineration of materials issued from photosynthesis, like wood and the other plants used to prepare the coatings, can be considered carbon neutral as the $\mathrm{CO}_{2}$ produced by the combustion was previously sequestrated by the vegetal [286], 
thereby decreasing its overall environmental impact. Furthermore, the heat produced by the incineration can be recovered to fuel different activities and avoid the consumption of unrenewable resources for energy production.

The implementation of passive systems is another great way to make wood surface treatments more ecological. The operational energy consumption of a building can be considerably reduced by using passive systems as compared to conventional systems [287]. For instance, the energy needed to heat and cool buildings, both residential and commercial, represent more than a third of their total energy consumption [288]. An approach studied over the last years to improve the energetic efficiency of buildings is the application of phase changing materials (PCMs) [289-292]. PCMs allow for the storage of thermal energy by melting the material and, subsequently, releasing this energy through solidification [293]. When using a material that melts near to room temperature $\left(20-22^{\circ} \mathrm{C}\right)$ in a building, it improves the thermal comfort of the habitants by sequestrating excessive heat, which diminishes the need for climatization. When the temperature falls below the melting point of the PCMs, the energy is released, reducing the need for heating. In a previous study, Mathis et al. demonstrated that composite walls containing PCMs could decrease the need for heating during the night by as much as $41 \%$ in timber-frame test huts simply by releasing heat accumulated during the day [294]. Two of the publications presented in this review detailed energy-storing coatings which contained PCMs. Kong et al. spray coated a wood substrate with a mixture of mesoporous polydivinylbenzene (PDVB) nanotubes, an industrial paraffin wax, and fluorine-containing $\mathrm{SiO}_{2}$ nanoparticles to obtain a surface with both superhydrophobicity and thermal energy storage [107]. The PDVB nanotubes could absorb and retain a large amount of paraffin wax (78.29\% in mass), leading to a latent fusion heat of $119.6 \mathrm{~J} / \mathrm{g}$. As a result, infrared thermography tests showed that the temperature of wood surfaces treated with the paraffin wax would change in a lesser extent than wood treated only with the nanotubes when exposed to heating (from a gain of $50{ }^{\circ} \mathrm{C}$ to $25^{\circ} \mathrm{C}$ ) and cooling $\left(50{ }^{\circ} \mathrm{C}\right.$ loss to $\left.20^{\circ} \mathrm{C}\right)$. However, the impact of the coating on the temperature of the room was not presented. Another functional coating was prepared by Qian et al. by encapsulating n-eicosane in $\mathrm{Fe}_{3} \mathrm{O}_{4} / \mathrm{SiO}_{2}$ microcapsules through a sol-gel method, leading to a wood surface with thermal energy storage and magnetism [155]. This coating showed a promising heat storage capacity, with a melting enthalpy of $170.9 \mathrm{~J} / \mathrm{g}$; however, no test was performed to assess its effect on the temperature of the wood or the room. The development of coatings with new types of passive systems could be a great avenue for future research.

The authors believe that three publications presented in this review have set themselves apart for their novelty in terms of ecological wood surface treatments. First, a coating was developed by Janesch et al. that was not only entirely bio-based, but also food safe [51]. The coating, made of bee wax and tung oil, was dip-coated on spruce specimens before being sprinkled with $\mathrm{NaCl}$. After a week-long drying, the salt could be removed with de-ionized water, leaving the organic layer with a well-defined micro-/nanoscale architecture. The so-casted coating was highly hydrophobic, with a water contact angle of $161^{\circ}$; however, it would not be considered superhydrophobic as its roll-off angle was way higher than $10^{\circ}$. Second, Zhang et al. prepared a jellified coating based on chitosan, gelatin and glycerol [52]. This coating had strong self-healing capabilities, being able to heal completely medium scratches simply by heating, and could easily be colored with water-soluble dyes. Its most innovative feature was its reusability, as it could simply be scraped from wood, dissolved in water and applied again. Finally, a silica-based coating with fire retardancy was prepared by Belykh et al. while using only industrial wastes [166]. The coating, which was made of by-products from the fabrication of ferrosilicon (sodium liquid glass) and gold mining activities (black shale), had a strong adhesion to the wood substrate and a lower mass loss after burning. While these treatments were not the best in terms of performances, they used unconventional approaches (food safety, reusability and wastes recycling), which should hopefully inspire future research. 


\subsection{Economical Aspects}

The last criterion that wood surface technologies must satisfy in order to be applied in real-life applications that will be discussed in this review revolves around their industrialization. While do-it-yourself methods can sometimes be applied, most treatments presented in this review rely on materials and equipment that are not readily available to everyone. Consequently, their use become dependent of the economy and the dynamics affecting the producers and the consumers. In other words, the viability of a wood treatment becomes conditional on whether an industry is willing to offer the treatment and whether the consumers are willing to buy it.

An important aspect of this dynamic is the price. The competition for treated wood is quite fierce, as wood products compete amongst themselves as well as against other construction materials [5]. Consequently, a wood surface treatment must be cheap to produce, as otherwise either the consumer will not be interested to buy it (too expensive) or the producer will not be interested to sell it (no profit). Accordingly, treatment methods such as dipping, spraying, and painting are quite attractive as they do not require any expensive equipment, are quickly applied, and are adaptable to different substrate shapes. These methods were adopted in different publications presented in this review to improve the characteristics of the wood surfaces, such as mechanical properties, thermal stability, dimensional stability and resistance to biodegradation. They were particularly prevalent to cast inorganic $[115-118,121,122,132,147,148,150,151,153,154,156-158,160-166,170,172]$ and organicinorganic composite $[87,88,103,105-107,109-114,125-127,129-131,134-137,142-144,146]$ co atings on different wood substrates. However, it is important to bear in mind that the application of these coatings can be lengthy; for instance, spraying and painting methods often require multiple layers, each of which must be dried before applying the next one. A similar pattern can be observed with dipping when building a layer-by-layer coating. Hydrothermal deposition was thoroughly studied to build different metallic coatings on wood; commonly, these treatments require multiple hours of dipping and even longer dryings. Likewise, sol-gels were extensively studied to build coatings based on $\mathrm{SiO}_{2}$ and $\mathrm{TiO}_{2}$, which also requires prolonged dipping periods, aging post-treatments and drying. Accordingly, these coating methods must allow for working in large batches in order to keep a good production rate. Brushing and dipping were also used to perform the surface impregnation of different protective agents into wood substrates, with similar limitations [238-241,244,246,247]. A quite different, yet interesting method was presented by Volokitin et al., who modified pine and birch with a thermal plasma to produce only a layer of thermo-modified wood [193]. The resulting timber displayed similar properties to thermo-modified wood (higher hydrophobicity, lower water absorption, dark colour), but was faster and cheaper to produce.

Some widely available and inexpensive chemicals were studied over the last five years as well. Among them, silica $\left(\mathrm{SiO}_{2}\right)$ received a particularly high attention as it showed great versatility in terms of properties, usage, and application methods. A first use for silica was as an additive in organic coatings to improve their mechanical properties $[90,95]$ or to create a durable micro-/nanoscale architecture into the coating to reach superhydrophobicity [104]. Similar to the latter, it was also used to create a micro-/nanoscale architecture directly on the wood surface before hydrophobization with very low surface free energy compounds $[104,106,111,113,117,118,120,126,128,130,132,133,151]$. Although application methods such as dipping and spraying were typical, Yang et al. developed a technique to create a mold of the surface of plants with natural superhydrophobicity, such as canna leaves [139] and rose petals [140]. Once filled with a $\mathrm{PVB} / \mathrm{SiO}_{2}$ composite, the mold allowed for the deposition of a perfect replica of the original plant surface on the wood. A last use for silica was to create a solid layer into which other materials could be encrusted to imbue new properties, such as photocatalytic activity [153,154] and photostability [196]. Although most researchers acquired their silica from a commercial supplier, some workers studied more durable options such as rice husk [90] and industrial wastes [166]. Another cheap, mildly toxic [295], and vastly studied component was 
$\mathrm{TiO}_{2}[89,91,94,110,125,129,131,147,148,153,154,158,197,205,208]$. Its uses were similar to silica's, in addition to which its UV absorption properties improved the photostability of the coated/treated wood. Finally, calcium carbonate $\left(\mathrm{CaCO}_{3}\right)$ was examined under different forms as an additive to organic coatings. When added to a waterborne acrylic resin as powdered oyster shell, it extended the burning time of the substrate from $18.00 \mathrm{~min}$ up to $29.67 \mathrm{~min}$ [97]. In order to prevent the premature degradation of organic UV absorbers in a clear acrylic coating, Queant et al. built $\mathrm{CaCO}_{3}$ microcapsules to encapsulate and protect the UV absorbers, increasing their efficiency over a prolonged period [82].

Apart from using cheap methods and materials, another way to make wood treatments worthwhile would be through added value. While plasma treatments require expensive equipment [20], they are quite scalable and allow for the preparation of durable coatings. Over the last five years, many authors studied the utilization of non-thermal plasma treatments to increase the surface free energy of wood with the objective to improve its wettability and the penetration of coatings [177,180,181,186,188,189]. Haase et al. found that pre-treating black spruce with a glow-discharge plasma would improve the penetration of coatings without increasing their adhesion [176]. However, they noted that it would improve the performances of solvent-borne coatings after $3024 \mathrm{~h}$ of artificial weathering, showing a better aging behavior. On the other hand, Zigon et al. showed that the tensile strength of coatings applied on weathered wood could increase by $20 \%$ with a FE-DBD plasma pre-treatment [178]. These results were supported by Peng et al. who also noted that dielectric barrier discharge plasma treatments would consequently reduce the delamination of a water-based primer applied on a beech substrate during a cross-cut test [190]. Accordingly, by virtue of their ability to enhance the penetration and bonding of different coatings, plasma treatments could be particularly useful in the case of wood products that cannot readily be refreshed, such as flooring and cabinets. In these scenario, the extra cost may be worth the gain in product quality and durability, as Kozak et al. discovered that consumers would be willing to spend more money for a product with a proportionally higher quality [296]. Moreover, the preparation of more expensive, premium grade wood products could have many supplementary advantages, such as diversifying the offer of wood products with different grades of goods and avoiding giving timber products an image of solely low cost and grade materials. It is also safer to offer an interesting warranty on high quality products with less chances of defect [297], which is a powerful marketing tool with high regards from many customers expecting to use wood in their projects $[298,299]$. Apart from plasma treatments, another method to create high quality wood surfaces was the encapsulation of organic coating additives. Yan and Peng studied the effect of adding urea-formaldehyde microcapsules with an acrylic resin core to water-based paints, which showed that the microcapsules imbued the paint with a strong self-healing capacity even when numerous and large cracks would appear [81]. Similarly, Queant et al. encapsulated organic UV-absorbers in $\mathrm{CaCO}_{3}$ microcapsules to reduce their premature degradation, which increased the photostability of a clear latex over $2500 \mathrm{~h}$ of artificial weathering [82]. Although the study of encapsulated coating fillers was fairly scarce over the last five years, the authors believe that it could be a promising route to develop new highly performant and durable wood surfaces.

In a more general fashion, the durability of wood surfaces and their properties is of crucial importance. No matter how performant a treatment is, it could hardly be considered a high-quality product if it loses its properties after just a while. The assessment of the most durable wood surface treatments was quite challenging for two main reasons. First, the methods used to test the properties of the wood surfaces, particularly their resistance to abrasion, were extremely variable, making comparison between the publications hazardous. Second, the durability tests, sometimes, were found to be unrepresentative of the stress the surfaces would encounter in their real condition of usage. As an example, sandpaper abrasion tests were extremely prominent for the durability of superhydrophobic surfaces, and often the only tested method. However, although such an abrasion may be representative for the surface of kitchen countertops or flooring, softer methods, such 
as sand and drop-impact abrasion would be more representative of the degradation of fences, sidings, and claddings, which are more likely to host a superhydrophobic surface. This consideration is of major importance, as the publications using both sandpaper abrasion and a softer test showed that their treatment would lose their superhydrophobicity quite rapidly when subjected to sandpaper, while the softer method would only affect it marginally $[114,121,123]$. Consequently, a wood surface treatment that could be perfectly fit for a certain function may be deemed as non-durable simply because the testing method used was inadequate for this type of treatment. For this reason, the authors would advise researchers to verify that their testing method is the most appropriate one for the end-use of the wood surface protection they are developing, and to consider using multiple complementary methods if needed. As a general statement, coatings based on inorganic materials such as $\mathrm{SiO}_{2}, \mathrm{TiO}_{2}, \mathrm{ZnO}$, and metals seemed like the most durable treatments, with high adhesion and resistance to mechanical (scratches, abrasion, and cutting) and chemical (acids, alkali and organic solvents) deterioration. Similar components and nanocellulose successfully acted as additives in organic coatings to improve their mechanical properties as well $[59,60,65,69,75,95,96]$. From all the different surface properties presented in this review, superhydrophobicity was the most tested for its performance following degradation. Although most superhydrophobic treatments lost their superhydrophobicity upon exposure to degradation, some of them stood out, such as Ou et al.'s silane composite coating, which would remain superhydrophobic or nearly superhydrophobic even after abrasion (sandpaper or tape peeling), knife scratching, immersion in ethanol, acids, and alkali, and exposition to UV radiations [115]. Similarly, Wang et al. prepared a composite coating with polydopamine, copper, and octadecylamine that would remain superhydrophobic after exposition to UV radiation or $24 \mathrm{~h}$ of soaking in $\mathrm{HCl}, \mathrm{NaOH}$, different organic solvents and boiling water [135]. A solution to the generally poor durability of superhydrophobic coating may be found in self-healing, as the restoration of the micro-/nanoscale architecture following mechanical damage can revert the loss of hydrophobicity [21]. Accordingly, different workers developed superhydrophobic coatings with self-healing capacities over the last five years, although some of them require a thermal stimulus for the actual healing to take place $[110,116]$. Conversely, a self-healing coating prepared by Wang et al. with $\mathrm{SiO}_{2}$ and perfluorooctyltriethoxysilane could not only self-repair upon taking damage without needing any external stimulus, but its self-healing ability could be replenished by spraying a coating solution [133]. Additionally, since superhydrophobicity (contact angle $>150^{\circ}$ ) offers arguably greater performance than actually necessary in practice [124], another solution would be to accept a lower contact angle to improve the durability of the wood surface. Since superhydrophobicity requires a quite strict and fragile architecture at the nanometric level, a rougher surface with low energy could allow for a satisfying hydrophobicity while being more resistant to damages. The durability of a flame-retardant system surface impregnated in poplar wood was tested by $\mathrm{He}$ et al. after a leaching experiment [241]. This system, establishing the synergistic effect of $\mathrm{SiO}_{2}$ and $\mathrm{K}_{2} \mathrm{CO}_{3}$ on the limiting oxygen index (LOI) of the treated poplar, allowed for the obtention of a satisfying $30.5 \%$ LOI even after leaching. Finally, wood with very high impact resistance was prepared by surface impregnating reactive chemicals prior to one-sided surface densification [232-234].

The visual aspect of wood is also a crucial element for wood surface treatments. Different studies have shown that the appearance of wood is of foremost importance to the consumer $[300,301]$, and the natural aspect of wood is usually well appreciated [302,303]. In regard to wood surface treatments, they represent an extra challenge to efficiently protect wood, as transparent surfaces cannot block UV radiations, which can lead to the photodegradation of the wood polymeric constituents and the delamination of clear coatings [24]. Satisfyingly, many publications over the last five years undertook to solve this problem by different means. Inorganic coatings made of different metallic oxides, mainly $\mathrm{ZnO}$, demonstrated great abilities to prevent color changes and chemical degradation in wood [122,147-149,154,156,160,161]. Similarly, organic-inorganic composite coatings $[105,109]$ and plasma-deposited coatings $[195,204,205,207,208]$ also used metallic ox- 
ides to achieve comparable performances. Clear organic coatings could be imbued with UV absorption when using different additives, among which wood extractives were particularly studied $[70,71,73-75,82,94]$. Grigsby discovered that a loading of less than $0.5 \%$ of condensed tannins and modified tannins in an acrylic coating could extend its life for longer than commercial HALS and phenolic stabilizers during accelerated and natural weathering [72]. However, the tannins would also make the coating darker. Indeed, another challenge associated with transparent wood treatments is for the treatment to be as clear as possible itself in order to preserve the natural color and gloss of pristine wood. Some workers noticed that their wood surface treatment would modify the appearance of wood $[44,59,93,96,171,206,225,226,230]$. However, it was very uncommon for authors to present the effect of their treatment on the transparency of wood although it is a very relevant data. This is particularly important when wood is not expected to be exposed to sun and undergo color changes, as the initial aspect modification will not be attenuated over time. Conversely, as stated by Sedliaciková [302], a significant proportion of the public is in fact looking for colored wood. While dyes and pigments are commonly used for this purpose, innovative new methods were developed over the last few years to obtain colored wood surfaces. Dagher et al. surface-impregnated a ferric sulfate solution in various hardwood species to produce colored complexes with their phenolic extractives, generating new colors directly inside of the wood [237]. Also, polystyrene colloidal microspheres with different acrylate-based copolymers were prepared by Liu and $\mathrm{Hu}$ to obtain organic coatings with colorful hues of green, red, and orange. Finally, many authors presented different transparent systems that could change color under stimuli such as UV radiations [161-163] and heat $[77-80,242]$.

As a general statement, coatings based on inorganic materials performed very well from an economic perspective, as many of them used cheap materials such as $\mathrm{SiO}_{2}$ and $\mathrm{TiO}_{2}$, simple methods, such as dipping and painting, and possessed a very high durability. An interesting example of such coating was provided by Wang et al. who produced a liquid-like $\mathrm{SiO}_{2}$-g-PDMS coating with a contact angle of $91^{\circ}$ [120]. Although this coating was far less hydrophobic than most coatings described in this review, it had the particularity to remain hydrophobic after prolonged contact with water. While most coatings undergo a transition from the Cassie-Baxter state to the Wenzel state after being in contact with water [304], which means that the air trapped in the micro-/nanoscale architecture is lost and that water can now adhere freely to the wood surface, this coating would keep a stable water contact angle even after $19 \mathrm{~d}$ of immersion. This feature could be very interesting to protect wood exposed outdoor in regions affected by heavy rains and in other circumstances where contact with water is extremely frequent. A very promising wood modification method was developed by Pouzet et al. to substitute the many hydroxyl groups at the surface of wood with hydrophobic fluorines $\left(\mathrm{F}^{-}\right)$by using gaseous $\mathrm{F}_{2}[215,216]$. The resulting wood surface displayed a high water contact angle $\left(120^{\circ}\right)$, a slower water absorption, and a very high durability as its performances remained unchanged after two years. Furthermore, it did not affect the color of Douglas fir and the water absorption could be further reduced by torrefaction [217]. Although the method relies on more expensive equipment and requires a rigorous sample preparation, its very short treatment time (5 min), scalability, low impact on the substrate appearance, the low cost of the chemicals involved, and its overall performances and durability shows great potential for the future.

The characteristics discussed in the last few pages are summarized in Table 3 This table only represents a summary of the aspects mentioned in the discussion, and should not be considered as the complete list of the characteristics for these trends. To conclude this discussion, this last paragraph will mention subjects the authors believe deserved more attention. First, the encapsulation of active compounds in stimuli-responsive microcapsules could represent a great way to increase the longevity of the properties of coatings. By protecting the active ingredients from external sources of degradation such as moisture, UV radiations, micro-organisms, and heat, properties such as photostability, fire-retardation, and fungal resistance could be extended to produce higher quality wood surfaces. Also, 
while protection from liquid water received the most attention of all the properties presented in this review, only a few authors presented results in regard to moisture buffering. Yet, this aspect is of major importance, as relative humidity alone can promote the growth of decay fungi and produce consequent dimensional changes in wood. Finally, none of the publications presented in this text presented the freeze-thaw properties of their wood surface treatment. However, an important fraction of the world population resides in areas where winter temperatures can reach below the freezing point. Consequently, this aspect could be a determinant for the longevity of exterior coatings.

Table 3. Characteristics of the different trends which were presented in the discussion.

\begin{tabular}{|c|c|c|}
\hline Categories & Trends & Characteristics \\
\hline \multirow{12}{*}{ Coatings } & Organic coatings-Reactives & Creation of interesting fire-retardant coatings. \\
\hline & Organic coatings-Bio-based reactives & $\begin{array}{c}\text { Great potential to replace less environment-friendly, oil-based monomers } \\
\text { when using the rights sources of raw materials; protection against } \\
\text { biodegradation. }\end{array}$ \\
\hline & Organic coatings-Other & $\begin{array}{l}\text { Can develop original properties such as sea-water resistance and bright } \\
\text { colors. }\end{array}$ \\
\hline & Organic coating additives-Bio-based & $\begin{array}{l}\text { Greater durability through increase mechanical resistance and } \\
\text { photostability; biodegradable upon leaching. }\end{array}$ \\
\hline & $\begin{array}{l}\text { Organic coating } \\
\text { additives-Non-biobased }\end{array}$ & $\begin{array}{l}\text { Wide variety of properties such as mechanical resistance, fire-retardation, } \\
\text { energy storage, and thermochromism; allows the encapsulation of } \\
\text { functional materials. }\end{array}$ \\
\hline & $\begin{array}{l}\text { Organic coating additives-Metallic } \\
\text { oxide nanoparticles }\end{array}$ & $\begin{array}{l}\text { Important properties such as mechanical resistance, hydrophobicity, and } \\
\text { photostability; cheap materials, but hazardous upon leaching. }\end{array}$ \\
\hline & Organic coating additives-Minerals & Important properties such as mechanical resistance and hydrophobicity. \\
\hline & $\begin{array}{c}\text { Organic-inorganic } \\
\text { composites-Nanoparticles + organic } \\
\text { resin }\end{array}$ & $\begin{array}{l}\text { Important properties such as mechanical resistance, hydrophobicity, } \\
\text { moisture buffering, and photostability; cheap materials and methods, but } \\
\text { hazardous upon leaching. }\end{array}$ \\
\hline & $\begin{array}{c}\text { Organic + inorganic } \\
\text { composites-Nanoparticles + low surface } \\
\text { energy components }\end{array}$ & $\begin{array}{l}\text { Important properties such as mechanical resistance, fire-retardancy, } \\
\text { hydrophobicity, moisture buffering, and photostability, good potential for } \\
\text { self-healing; cheap materials and methods, but hazardous upon leaching. }\end{array}$ \\
\hline & Organic + inorganic composites-Others & Important properties such as fire-retardancy and hydrophobicity. \\
\hline & $\begin{array}{l}\text { Inorganic coatings-Metallic oxides and } \\
\text { silica }\end{array}$ & $\begin{array}{l}\text { Important properties such as mechanical resistance, fire-retardancy, } \\
\text { hydrophobicity, moisture buffering, and photostability, good potential for } \\
\text { self-healing; cheap materials and methods, but hazardous upon leaching. }\end{array}$ \\
\hline & Inorganic coatings-Others & $\begin{array}{l}\text { Important properties such as mechanical resistance, fire-retardancy, } \\
\text { hydrophobicity, and photostability; interesting properties, e.g., } \\
\text { magnetism. }\end{array}$ \\
\hline \multirow{4}{*}{ Surface modification } & Plasma-Hydrophilization & $\begin{array}{l}\text { Expensive, but produces high quality timber products with improved } \\
\text { coatings adhesion and durability. }\end{array}$ \\
\hline & Plasma-Coating deposition & $\begin{array}{l}\text { Important properties such as hydrophobicity and photostability; } \\
\text { expensive, but solvent-free. }\end{array}$ \\
\hline & $\begin{array}{l}\text { Other modifications-Chemical } \\
\text { modification }\end{array}$ & $\begin{array}{c}\text { Important properties such as hydrophobicity and moisture buffering; no } \\
\text { or low leaching, can be solvent-free. }\end{array}$ \\
\hline & Other modifications-Carbonization & $\begin{array}{l}\text { Solvent-free methods to improve the durability against biodegradation, } \\
\text { but heavily affects the color of wood. }\end{array}$ \\
\hline \multirow[b]{2}{*}{ Surface impregnation } & Impregnation of reactives & Improvement of the hardness of wood surfaces; development of colors. \\
\hline & Impregnation of material & $\begin{array}{l}\text { Important properties such as fire-retardancy and hydrophobicity; lower } \\
\text { WPG than pressure impregnation. }\end{array}$ \\
\hline
\end{tabular}

\section{Conclusions}

Increasing the use of wood in construction is a great way to combat climate change while developing an aesthetic and durable building stock. In order to achieve this goal, work must be undertaken to convince the public and architects to integrate more wood in buildings. Scientists can assist in this task by making wood more appealing, either by 
protecting it from hazards such as combustion, biodegradation and photodegradation, or developing new properties, e.g., self-healing and self-cleaning.

Over the last five years, at least 212 publications were written to describe innovative methods to improve the surface of wood. In this review, these publications were divided into different trends based on the chemical composition and the treatment method they described. After introducing the different trends and the publications that comprise them, various normative, ecological, and economical challenges associated with the protection of wood were presented. The way different trends could answer to these challenges was then discussed, leading to a certain hierarchy for potential real-life applications. Each section was finally concluded by describing the individual treatments that showed the most originality or performance toward the discussed subject.

The discussed aspects of wood protection showed that trends including inorganic nanoparticles such as silica and metallic oxides showed an incredible potential for different applications. They could first answer to normative principles by granting fire-retardancy to the protected wood and reducing the hazards of biodegradation through a drastic diminution of the uptake of water. From an economical point of view, they use cheap and abundant materials, are applicable with easy methods, are highly durable, and can efficiently protect the wood polymeric constituent from UV radiations. However, the leaching of these nanoparticles into the environment may represent a serious hazard in the long run, as they possess a certain toxicity and cannot be naturally degraded, which will lead only to increasing concentrations.

This review should help researchers to plan their future projects with a broader perspective of the different criteria that wood surface improvements need to meet in order to be introduced in the society. By focusing on the development of cheap, durable, and environment-friendly treatments to solve issues such as combustibility, photodegradation, and biodegradation, a new generation of wood surface technology could revolutionize the perception of the public toward wood. The authors hope that the reflections shared in the review will help to accelerate the transition of new and innovative wood treatments from the laboratory to the market so that they can contribute to increase the use of wood in buildings.

Author Contributions: Structure of the work, P.B.; Review of the literature and writing of the original draft, S.P.; review and final editing of the paper, S.P. and P.B. All authors have read and agreed to the published version of the manuscript.

Funding: This research was funded by Natural Sciences and Engineering Research Council of Canada, grant number IRCPJ 461745- 18 and RDCPJ 524504-18.

Institutional Review Board Statement: Not applicable.

Informed Consent Statement: Not applicable.

Data Availability Statement: Not applicable.

Acknowledgments: The authors are grateful to the Natural Sciences and Engineering Research Council of Canada as well as the industrial partners of the NSERC industrial chair on eco-responsible wood construction (CIRCERB).

Conflicts of Interest: The authors declare no conflict of interest.

\section{References}

1. Lippke, B.R.; Bowyer, J.; Meil, J. CORRIM: Life-Cycle Environmental Performance of Renewable Building Materials. For. Prod. J. 2004, 54, 7-19.

2. Nath, S.K. Use Wood-Combat Climate Change. In Wood Is Good: Current Trends and Future Prospects in Wood Utilization; Pandey, K.K., Ramakantha, V., Chauhan, S.S., Kumar, A.N.A., Eds.; Springer: Singapore, 2017; pp. 469-478. [CrossRef]

3. Food and Agriculture Organization of the United Nations. Action Urged to Promote Wood as a Sustainable Construction Material. Available online: http:/ / www.fao.org/forestry/news/99169/en/ (accessed on 3 October 2021).

4. Reinprecht, L. Wood Deterioration, Protection, and Maintenance; John Wileys \& Sons: Chichester, UK, 2016 ; ISBN 9781119106531.

5. Hill, C. Wood Modification: Chemical, Thermal and Other Processes; John Wileys \& Sons: Chichester, UK, 2006; ISBN 978-0-470-02172-9. 
6. Wang, X.; Zhang, Y.; Yu, Z.; Qi, C. Properties of Fast-Growing Poplar Wood Simultaneously Treated with Dye and Flame Retardant. Eur. J. Wood Wood Prod. 2017, 75, 325-333. [CrossRef]

7. Kumar, S. Chemical modification of wood. Soc. Wood Sci. Technol. 1994, 26, 270-280.

8. Wang, C.; Piao, C. From Hydrophilicity to Hydrophobicity: A Critical Review-Part II: Hydrophobic Conversion. Wood Fiber 2010, 42, 490-510.

9. Yuan, J.; Hu, Y.; Li, L.; Cheng, F. The Mechanical Strength Change of Wood Modified with DMDHEU. BioResources 2013, 8, 1076-1088. [CrossRef]

10. .Kocaefe, D.; Huang, X.; Kocaefe, Y. Dimensional Stabilization of Wood. Curr. For. Rep. 2015, 1, 151-161. [CrossRef]

11. Bekhta, P.; Proszyk, S.; Krystofiak, T.; Mamonova, M.; Pinkowski, G.; Lis, B. Effect of Thermomechanical Densification on Surface Roughness of Wood Veneers. Wood Mater. Sci. Eng. 2014, 9, 233-245. [CrossRef]

12. Pertuzzatti, A.; Missio, A.L.; de Cademartori, P.H.G.; Santini, E.J.; Haselein, C.R.; Berger, C.; Gatto, D.A.; Tondi, G. Effect of Process Parameters in the Thermomechanical Densification of Pinus Elliottii and Eucalyptus Grandis Fast-Growing Wood. BioResources 2018, 13, 1576-1590. [CrossRef]

13. Ross, A.S. Organic Preservative Systems for the Protection of Wood Windows and Doors. In Development of Commercial Wood Preservatives: Efficacy, Environmental, and Health Issues; Schultz, T.P., Militz, H., Freeman, M.H., Goodell, B., Nicholas, D.D., Eds.; American Chemical Society: Washington, DC, USA, 2008; Volume 982, pp. 470-479. [CrossRef]

14. Schultz, T.; Nicholas, D. A Brief Overview of Non-Arsenical Wood Preservative Systems. In Wood Deterioration and Preservation: Advances in Our Changing World; Goodell, B., Nicholas, D.D., Schultz, T.P., Eds.; American Chemical Society: Washington, DC, USA, 2003; pp. 420-432.

15. Laks, P.E. Wood Preservative Fungicides and the American Wood Preservers' Association Use Category System. In Development of Commercial Wood Preservatives: Efficacy, Environmental, and Health Issues; Schultz, T.P., Militz, H., Freeman, M.H., Goodell, B., Nicholas, D.D., Eds.; American Chemical Society: Washington, DC, USA, 2008; Volume 982, pp. 228-240. [CrossRef]

16. Leightley, L.E. Protection of Wood Using Combinations of Biocides. In Wood Deterioration and Preservation: Advances in Our Changing World; Goodell, B., Nicholas, D.D., Schultz, T.P., Eds.; American Chemical Society: Washington, DC, USA, 2003; pp. 390-398.

17. Freeman, M.H. Wood Preservative Formulation Development and Systems: Organic and Inorganic Based Systems. In Development of Commercial Wood Preservatives: Efficacy, Environmental, and Health Issues; Schultz, T.P., Militz, H., Freeman, M.H., Goodell, B., Nicholas, D.D., Eds.; American Chemical Society: Washington, DC, USA, 2008; Volume 982, pp. 408-426.

18. Girardi, F.; Cappelletto, E.; Sandak, J.; Bochicchio, G.; Tessadri, B.; Palanti, S.; Feci, E.; Di Maggio, R. Hybrid Organic-Inorganic Materials as Coatings for Protecting Wood. Prog. Org. Coat. 2014, 77, 449-457. [CrossRef]

19. Nikolic, M.; Lawther, J.M.; Sanadi, A.R. Use of Nanofillers in Wood Coatings: A Scientific Review. J. Coat. Technol. Res. 2015, 12, 445-461. [CrossRef]

20. Dimitrakellis, P.; Gogolides, E. Hydrophobic and Superhydrophobic Surfaces Fabricated Using Atmospheric Pressure Cold Plasma Technology: A Review. Adv. Colloid Interface Sci. 2018, 254, 1-21. [CrossRef]

21. Kobina Sam, E.; Kobina Sam, D.; Lv, X.; Liu, B.; Xiao, X.; Gong, S.; Yu, W.; Chen, J.; Liu, J. Recent Development in the Fabrication of Self-Healing Superhydrophobic Surfaces. Chem. Eng. J. 2019, 373, 531-546. [CrossRef]

22. Teng, T.-J.; Mat Arip, M.N.; Sudesh, K.; Nemoikina, A.; Jalaludin, Z.; Ng, E.-P.; Lee, H.-L. Conventional Technology and Nanotechnology in Wood Preservation: A Review. BioResources 2018, 13, 9220-9252. [CrossRef]

23. George, B.; Suttie, E.; Merlin, A.; Deglise, X. Photodegradation and Photostabilisation of Wood-The State of the Art. Polym. Degrad. Stab. 2005, 88, 268-274. [CrossRef]

24. Cogulet, A.; Blanchet, P.; Landry, V. The Multifactorial Aspect of Wood Weathering: A Review Based on a Holistic Approach of Wood Degradation Protected by Clear Coating. BioResources 2018, 13, 2116-2138. [CrossRef]

25. Evans, P.D.; Haase, J.G.; Shakri, A.; Seman, B.M.; Kiguchi, M. The Search for Durable Exterior Clear Coatings for Wood. Coatings 2015, 5, 830-864. [CrossRef]

26. Barber, D.; Gerard, R. Summary of the Fire Protection Foundation Report-Fire Safety Challenges of Tall Wood Buildings. Fire Sci. Rev. 2015, 4, 1-15. [CrossRef]

27. Popescu, C.M.; Pfriem, A. Treatments and Modification to Improve the Reaction to Fire of Wood and Wood Based Products-An Overview. Fire Mater. 2020, 44, 100-111. [CrossRef]

28. Vakhitova, L.N. Fire Retardant Nanocoating for Wood Protection. In Nanotechnology in Eco-Efficient Construction: Materials, Processes and Applications; Amirkhanian, F.P.-T., Diamanti, M.V., Nazari, A., Goran-Granqvist, C., Pruna, A., Amirkhanian, S., Eds.; Elsevier: Philadelphia, PA, USA, 2018; pp. 361-391. [CrossRef]

29. Page, M.J.; McKenzie, J.E.; Bossuyt, P.M.; Boutron, I.; Hoffmann, T.C.; Mulrow, C.D.; Shamseer, L.; Tetzlaff, J.M.; Akl, E.A.; Brennan, S.E.; et al. The PRISMA 2020 Statement: An Updated Guideline for Reporting Systematic Reviews. BMJ 2021, 372 , n71. [CrossRef]

30. Ma, T.; Li, L.; Wang, Q.; Guo, C. Construction of Intumescent Flame Retardant and Hydrophobic Coating on Wood Substrates Based on Thiol-Ene Click Chemistry without Photoinitiators. Compos. Part B Eng. 2019, 177, 107357. [CrossRef]

31. Wang, T.; Liu, T.; Ma, T.; Li, L.; Wang, Q.; Guo, C. Study on Degradation of Phosphorus and Nitrogen Composite UV-Cured Flame Retardant Coating on Wood Surface. Prog. Org. Coat. 2018, 124, 240-248. [CrossRef] 
32. Mali, P.P.; Pawar, N.S.; Sonawane, N.S.; Patil, V.; Patil, R. UV Curable Flame Retardant Coating: A Novel Synthetic Approach of Trispiperazido Phosphate Based Reactive Diluent. Pigment Resin Technol. 2020, 50, 271-283. [CrossRef]

33. Wang, T.; Li, L.; Cao, Y.; Wang, Q.; Guo, C. Preparation and Flame Retardancy of Castor Oil Based UV-Cured Flame Retardant Coating Containing P/Si/S on Wood Surface. Ind. Crops Prod. 2019, 130, 562-570. [CrossRef]

34. Lokhande, G.; Chambhare, S.; Jagtap, R. Synthesis and Properties of Phosphate-Based Diacrylate Reactive Diluent Applied to UV-Curable Flame-Retardant Wood Coating. J. Coat. Technol. Res. 2017, 14, 255-266. [CrossRef]

35. Mulge, S.; Mestry, S.; Naik, D.; Mhaske, S. Phosphorus-Containing Reactive Agent for UV-Curable Flame-Retardant Wood Coating. J. Coat. Technol. Res. 2019, 16, 1493-1502. [CrossRef]

36. Paquet, C.; Schmitt, T.; Klemberg-Sapieha, J.E.; Morin, J.-F.; Landry, V. Self-Healing UV Curable Acrylate Coatings for Wood Finishing System, Part 1: Impact of the Formulation on Self-Healing Efficiency. Coatings 2020, 10, 770. [CrossRef]

37. Rawat, R.S.; Chouhan, N.; Talwar, M.; Diwan, R.K.; Tyagi, A.K. UV Coatings for Wooden Surfaces. Prog. Org. Coat. 2019, 135, 490-495. [CrossRef]

38. Wang, J.; Wu, H.; Liu, R.; Long, L.; Xu, J.; Chen, M.; Qiu, H. Preparation of a Fast Water-Based UV Cured Polyurethane-Acrylate Wood Coating and the Effect of Coating Amount on the Surface Properties of Oak (Quercus alba L.). Polymers 2019, $11,1414$. [CrossRef]

39. Raychura, A.J.; Dholakiya, B.Z.; Patel, K.I.; Jauhari, S. Development of Non-Traditional Vegetable-Oil-Based Two-Pack Polyurethane for Wood-Finished Coating: An Alternative Approach. ChemistrySelect 2018, 3, 10837-10842. [CrossRef]

40. Raychura, A.J.; Jauhari, S.; Prajapati, V.S.; Dholakiya, B.Z. Synthesis and Performance Evaluation of Vegetable Oil Based Wood Finish Polyurethane Coating. Bioresour. Technol. Rep. 2018, 3, 88-94. [CrossRef]

41. Lazim, A.M.; Azfaralariff, A.; Azman, I.; Arip, M.N.M.; Zubairi, S.I.; Mohd Kaus, N.H.; Nazir, N.; Mohamad, M.; Kamil, A.; Azzahari, A.D.; et al. Improving Wood Durability against G. Trabeum and C. Versicolor Using Starch Based Antifungal Coating from Dioscorea hispida sp. J. Taiwan Inst. Chem. Eng. 2020, 115, 242-250. [CrossRef]

42. Lazim, A.M.; Azman, I.; Yusoff, S.F.M.; Hassan, N.I.; Fazry, S.; Arip, M.N.M. Synthesis and Characterization of Dioscorea Hispida Sp. Tuber Starch-Polyacrylamide Wood Coating and Its Facile Inhibitory towards Pycnoporus Sanguineus and Coptotermes curvignathus. Prog. Org. Coat. 2016, 99, 182-190. [CrossRef]

43. Dixit, A.; Wazarkar, K.; Sabnis, A.S. Antimicrobial UV Curable Wood Coatings Based on Citric Acid. Pigment Resin Technol. 2021, in press. [CrossRef]

44. Kong, L.; Xu, D.; He, Z.; Wang, F.; Gui, S.; Fan, J.; Pan, X.; Dai, X.; Dong, X.; Liu, B.; et al. Nanocellulose-Reinforced Polyurethane for Waterborne Wood Coating. Molecules 2019, 24, 3151. [CrossRef]

45. Li, X.; Wang, D.; Zhao, L.; Hou, X.; Liu, L.; Feng, B.; Li, M.; Zheng, P.; Zhao, X.; Wei, S. UV LED Curable Epoxy Soybean-Oil-Based Waterborne PUA Resin for Wood Coatings. Prog. Org. Coat. 2021, 151, 105942. [CrossRef]

46. Szubert, K. Synthesis of Organofunctional Silane from Rapeseed Oil and Its Application as a Coating Material. Cellulose 2018, 25, 6269-6278. [CrossRef]

47. Mehta, L.B.; Wadgaonkar, K.K.; Jagtap, R.N. Synthesis and Characterization of High Bio-Based Content Unsaturated Polyester Resin for Wood Coating from Itaconic Acid: Effect of Various Reactive Diluents as an Alternative to Styrene. J. Dispers. Sci. Technol. 2019, 40, 756-765. [CrossRef]

48. Niu, K.; Song, K. Surface Coating and Interfacial Properties of Hot-Waxed Wood Using Modified Polyethylene Wax. Prog. Org. Coat. 2021, 150, 105947. [CrossRef]

49. Raphael, W.; Martel, T.; Landry, V.; Tavares, J.R. Surface Engineering of Wood Substrates to Impart Barrier Properties: A Photochemical Approach. Wood Sci. Technol. 2018, 52, 193-207. [CrossRef]

50. Merighi, S.; Mazzocchetti, L.; Benelli, T.; Maccaferri, E.; Zucchelli, A.; D’Amore, A.; Giorgini, L. A New Wood Surface FlameRetardant Based on Poly-m-Aramid Electrospun Nanofibers. Polym. Eng. Sci. 2019, 59, 2541-2549. [CrossRef]

51. Janesch, J.; Arminger, B.; Gindl-Altmutter, W.; Hansmann, C. Superhydrophobic Coatings on Wood Made of Plant Oil and Natural Wax. Prog. Org. Coat. 2020, 148, 105891. [CrossRef]

52. Zhang, L.; Huang, Y.; Sun, P.; Hai, Y.; Jiang, S. A Self-Healing, Recyclable, and Degradable Fire-Retardant Gelatin-Based Biogel Coating for Green Buildings. Soft Matter 2021, 17, 5231-5239. [CrossRef] [PubMed]

53. Esfandiar, N.; Elmi, F.; Omidzahir, S. Study of the Structural Properties and Degradation of Coated Wood with Polydopamine/Hydroxyapatite/Chitosan Hybrid Nanocomposite in Seawater. Cellulose 2020, 27, 7779-7790. [CrossRef]

54. Liu, Y.; Hu, J. Investigation of Polystyrene-Based Microspheres from Different Copolymers and Their Structural Color Coatings on Wood Surface. Coatings 2021, 11, 14. [CrossRef]

55. Rosu, L.; Varganici, C.D.; Mustata, F.; Rosu, D.; Rosca, I.; Rusu, T. Epoxy Coatings Based on Modified Vegetable Oils for Wood Surface Protection against Fungal Degradation. ACS Appl. Mater. Interfaces 2020, 12, 14443-14458. [CrossRef] [PubMed]

56. .Ma, T.; Li, L.; Liu, Z.; Zhang, J.; Guo, C.; Wang, Q. A Facile Strategy to Construct Vegetable Oil-Based, Fire-Retardant, Transparent and Mussel Adhesive Intumescent Coating for Wood Substrates. Ind. Crops Prod. 2020, 154, 112628. [CrossRef]

57. Gordobil, O.; Herrera, R.; Llano-Ponte, R.; Labidi, J. Esterified Organosolv Lignin as Hydrophobic Agent for Use on Wood Products. Prog. Org. Coat. 2017, 103, 143-151. [CrossRef]

58. Zikeli, F.; Vinciguerra, V.; D’Annibale, A.; Capitani, D.; Romagnoli, M.; Mugnozza, G.S. Preparation of Lignin Nanoparticles from Wood Waste for Wood Surface Treatment. Nanomaterials 2019, 9, 281. [CrossRef] 
59. Kluge, M.; Veigel, S.; Pinkl, S.; Henniges, U.; Zollfrank, C.; Rössler, A.; Gindl-Altmutter, W. Nanocellulosic Fillers for Waterborne Wood Coatings: Reinforcement Effect on Free-Standing Coating Films. Wood Sci. Technol. 2017, 51, 601-613. [CrossRef]

60. Yoo, Y.; Youngblood, J.P. Tung Oil Wood Finishes with Improved Weathering, Durability, and Scratch Performance by Addition of Cellulose Nanocrystals. ACS Appl. Mater. Interfaces 2017, 9, 24936-24946. [CrossRef]

61. Cheng, D.; Wen, Y.; An, X.; Zhu, X.; Ni, Y. TEMPO-Oxidized Cellulose Nanofibers (TOCNs) as a Green Reinforcement for Waterborne Polyurethane Coating (WPU) on Wood. Carbohydr. Polym. 2016, 151, 326-334. [CrossRef] [PubMed]

62. Cataldi, A.; Esposito Corcione, C.; Frigione, M.; Pegoretti, A. Photocurable Resin/Nanocellulose Composite Coatings for Wood Protection. Prog. Org. Coat. 2017, 106, 128-136. [CrossRef]

63. Yang, F.; Wu, Y.; Zhang, S.; Zhang, H.; Zhao, S.; Zhang, J.; Fei, B. Mechanical and Thermal Properties of Waterborne Polyurethane Coating Modified through One-Step Cellulose Nanocrystals/Graphene Materials Sols Method. Coatings 2020, 10, 40. [CrossRef]

64. Tian, Y.; Gao, Y.; Pan, X.; Liu, Q.; Wang, J.; Jin, M.; Li, J. Renewable UV-Curable Polyester Methacrylate/Cellulose Nanocrystals Composite Resin for Wood Waterproof Coating. Nanotechnology 2021, 32, 275703. [CrossRef] [PubMed]

65. Veigel, S.; Lems, E.M.; Grüll, G.; Hansmann, C.; Rosenau, T.; Zimmermann, T.; Gindl-Altmutter, W. Simple Green Route to Performance Improvement of Fully Bio-Based Linseed Oil Coating Using Nanofibrillated Cellulose. Polymers 2017, 9, 425. [CrossRef]

66. Kaboorani, A.; Auclair, N.; Riedl, B.; Landry, V. Mechanical Properties of UV-Cured Cellulose Nanocrystal (CNC) Nanocomposite Coating for Wood Furniture. Prog. Org. Coat. 2017, 104, 91-96. [CrossRef]

67. Kaboorani, A.; Auclair, N.; Riedl, B.; Landry, V. Physical and Morphological Properties of UV-Cured Cellulose Nanocrystal (CNC) Based Nanocomposite Coatings for Wood Furniture. Prog. Org. Coat. 2016, 93, 17-22. [CrossRef]

68. Kaboorani, A.; Auclair, N.; Riedl, B.; Hosseinaei, O.; Wang, S. Cellulose Nanocrystal (CNC)-Based Nanocomposites for UV Curable High-Solid Coating Systems. J. Coat. Technol. Res. 2017, 14, 1137-1145. [CrossRef]

69. Cheng, L.; Ren, S.; Lu, X. Application of Eco-Friendly waterborne Polyurethane Composite Coating Incorporated with Nano Cellulose Crystalline and Silver Nano Particles on Wood Antibacterial Board. Polymers 2020, 12, 407. [CrossRef]

70. Peng, Y.; Wang, Y.; Chen, P.; Wang, W.; Cao, J. Enhancing Weathering Resistance of Wood by Using Bark Extractives as Natural Photostabilizers in Polyurethane-Acrylate Coating. Prog. Org. Coat. 2020, 145, 105665. [CrossRef]

71. Özgenç, Ö.; Durmaz, S.; Şahin, S.; Boyaci, İ.H. Evaluation of the Weathering Resistance of Waterborne Acrylic- and Alkyd-Based Coatings Containing HALS, UV Absorber, and Bark Extracts on Wood Surfaces. J. Coat. Technol. Res. 2020, 17, 461-475. [CrossRef]

72. Grigsby, W.J. Photooxidative Stability Provided by Condensed Tannin Additives in Acrylic-Based Surface Coatings on Exterior Exposure. J. Coat. Technol. Res. 2018, 15, 1273-1282. [CrossRef]

73. Tomak, E.D.; Yazici, O.A.; Sam Parmak, E.D.; Gonultas, O. Influence of Tannin Containing Coatings on Weathering Resistance of Wood: Combination with Zinc and Cerium Oxide Nanoparticles. Polym. Degrad. Stab. 2018, 152, 289-296. [CrossRef]

74. Tomak, E.D.; Arican, F.; Gonultas, O.; Sam Parmak, E.D. Influence of Tannin Containing Coatings on Weathering Resistance of Wood: Water Based Transparent and Opaque Coatings. Polym. Degrad. Stab. 2018, 151, 152-159. [CrossRef]

75. Huang, Y.; Feng, Q.; Ye, C.; Nair, S.S.; Yan, N. Incorporation of Ligno-Cellulose Nanofibrils and Bark Extractives in Water-Based Coatings for Improved Wood Protection. Prog. Org. Coat. 2020, 138, 105210. [CrossRef]

76. Yan, X.; Wang, L.; Qian, X. Effect of High-Temperature Calcined Wheat Straw Powder after Lignin Removal on Properties of Waterborne Wood Coatings. Coatings 2019, 9, 444. [CrossRef]

77. Zhu, X.; Liu, Y.; Li, Z.; Wang, W. Thermochromic Microcapsules with Highly Transparent Shells Obtained through In-Situ Polymerization of Urea Formaldehyde around Thermochromic Cores for Smart Wood Coatings. Sci. Rep. 2018, 8, 4015. [CrossRef]

78. Yan, X.; Wang, L.; Qian, X. Effect of Coating Process on Performance of Reversible Thermochromic Waterborne Coatings for Chinese Fir. Coatings 2020, 10, 223. [CrossRef]

79. Li, Y.; Li, J. Fabrication of Reversible Thermoresponsive Thin Films on Wood Surfaces with Hydrophobic Performance. Prog. Org. Coat. 2018, 119, 15-22. [CrossRef]

80. Li, Y.; Hui, B.; Li, G.; Li, J. Fabrication of Smart Wood with Reversible Thermoresponsive Performance. J. Mater. Sci. 2017, 52, 7688-7697. [CrossRef]

81. Yan, X.; Peng, W. Preparation of Microcapsules of Urea Formaldehyde Resin Coated Waterborne Coatings and Their Effect on Properties of Wood Crackle Coating. Coatings 2020, 10, 764. [CrossRef]

82. Queant, C.; Blanchet, P.; Landry, V.; Schorr, D. Effect of Adding UV Absorbers Embedded in Carbonate Calcium Templates Covered with Light Responsive Polymer into a Clear Wood Coating. Coatings 2018, 8, 265. [CrossRef]

83. Yan, X.; Wang, L.; Qian, X. Effect of Urea-Formaldehyde-Coated Epoxy Microcapsule Modification on Gloss, Toughness and Chromatic Distortion of Acrylic Copolymers Waterborne Coating. Coatings 2019, 9, 239. [CrossRef]

84. Hermann, A.; Burr, D.; Landry, V. Comparative Study of the Impact of Additives against Oxygen Inhibition on Pendulum Hardness and Abrasion Resistance for UV-Curable Wood Finishes. Prog. Org. Coat. 2021, 156, 106266. [CrossRef]

85. Jia, S.; Lu, X.; Luo, S.; Qing, Y.; Yan, N.; Wu, Y. Efficiently Texturing Hierarchical Epoxy Layer for Smart Superhydrophobic Surfaces with Excellent Durability and Exceptional Stability Exposed to Fire. Chem. Eng. J. 2018, 348, 212-223. [CrossRef]

86. Wu, Y.; Wu, X.; Yang, F.; Ye, J. Preparation and Characterization of Waterborne UV Lacquer Product Modified by Zinc Oxide with Flower Shape. Polymers 2020, 12, 668. [CrossRef] 
87. Zhan, K.; Xia, S.; Lu, Q.; Cheng, R.; Jiang, H.; Yi, T.; Morrell, J.; Yang, L.; Xie, L.; Lei, H.; et al. Superhydrophobic Wood Surface Fabricated by $\mathrm{Cu}_{2} \mathrm{O}$ Nano-Particles and Stearic Acid: Its Acid/Alkali and Wear Resistance. Holzforschung 2021, 75, 917-931. [CrossRef]

88. Zhan, K.; Lu, Q.; Xia, S.; Guo, C.; Zhao, S.; Gao, W.; Yang, L.; Morrell, J.J.; Yi, T.; Xie, L.; et al. A Cost Effective Strategy to Fabricate STA@PF@Cu $\mathrm{Cu}_{2} \mathrm{O}$ Hierarchical Structure on Wood Surface: Aimed at Superhydrophobic Modification. Wood Sci. Technol. 2021, 55, 565-583. [CrossRef]

89. Sevda, B.T.; Ayfer, D.C.; Turgay, O. The Synergistic Effect of Intumescent Coating Containing Titanium Dioxide and Antimony Trioxide onto Spruce and Alder Wood Species. J. Build. Eng. 2020, 31, 101407. [CrossRef]

90. Guo, S.; Wang, D.; Shi, J.; Li, X.; Feng, B.; Meng, L.; Cai, Z.; Qiu, H.; Wei, S. Study on Waterborne Acrylate Coatings Modified with Biomass Silicon. Prog. Org. Coat. 2019, 135, 601-607. [CrossRef]

91. Pantano, D.; Neubauer, N.; Navratilova, J.; Scifo, L.; Civardi, C.; Stone, V.; Von Der Kammer, F.; Müller, P.; Sobrido, M.S.; Angeletti, B.; et al. Transformations of Nanoenabled Copper Formulations Govern Release, Antifungal Effectiveness, and Sustainability throughout the Wood Protection Lifecycle. Environ. Sci. Technol. 2018, 52, 1128-1138. [CrossRef] [PubMed]

92. Silva-Castro, I.; Casados-Sanz, M.; Alonso-Cortés, A.L.; Martín-Ramos, P.; Martín-Gil, J.; Acuña-Rello, L. Chitosan-Based Coatings to Prevent the Decay of Populus spp. Wood Caused by Trametes Versicolor. Coatings 2018, 8, 415. [CrossRef]

93. Boivin, G.; Ritcey, A.M.; Landry, V. The Effect of Silver Nanoparticles on the Black-Stain Resistance of Acrylic Resin for Translucent Wood Coating Application. BioResources 2019, 14, 6353-6369. [CrossRef]

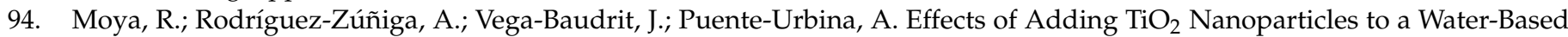
Varnish for Wood Applied to Nine Tropical Woods of Costa Rica Exposed to Natural and Accelerated Weathering. J. Coat. Technol. Res. 2017, 14, 141-152. [CrossRef]

95. Yan, X.-X.; Cai, Y.-T.; Xu, G.-Y.; Xu, W. Mechanical and Optical Properties of Waterborne UV Curing Coating Modified by Silica. In Proceedings of the 4th Annual International Conference on Material Science and Engineering (ICMSE 2016), Guangzhou, China, 17-19 June 2016; pp. 370-375. [CrossRef]

96. Weththimuni, M.L.; Capsoni, D.; Malagodi, M.; Milanese, C.; Licchelli, M. Shellac/Nanoparticles Dispersions as Protective Materials for Wood. Appl. Phys. A Mater. Sci. Process. 2016, 122, 1058. [CrossRef]

97. Atienza, R.A.G.; Cruz, T.J.F. Utilizing Philippine Cupped Oyster (Crassostrea Iredalei) Shell Powder and Waterborne Acrylic Resin as a Fire Retardant Coating for Marine Wood. In Proceedings of the 9th IEEE Integrated STEM Education Conference (ISEC 2019), Princeton, NJ, USA, 16 March 2019; pp. 9-10. [CrossRef]

98. Wu, J.; Wang, M.; Guo, H. Synergistic Flame Retardant Effects of Different Zeolites on Intumescent Fire Retardant Coating for Wood. BioResources 2017, 12, 5369-5382. [CrossRef]

99. Esmailpour, A.; Majidi, R.; Taghiyari, H.R.; Ganjkhani, M.; Armaki, S.M.M.; Papadopoulos, A.N. Improving Fire Retardancy of Beechwood by Graphene. Polymers 2020, 12, 303. [CrossRef] [PubMed]

100. Taghiyari, H.R.; Tajvidi, M.; Soltani, A.; Esmailpour, A.; Khodadoosti, G.; Jafarzadeh, H.; Militz, H.; Papadopoulos, A.N. Improving Fire Retardancy of Unheated and Heat-Treated Fir Wood by Nano-Sepiolite. Eur. J. Wood Wood Prod. 2021, 79, 841-849. [CrossRef]

101. Kolya, H.; Kang, C.W. Polyvinyl Acetate/Reduced Graphene Oxide-Poly (Diallyl Dimethylammonium Chloride) Composite Coated Wood Surface Reveals Improved Hydrophobicity. Prog. Org. Coat. 2021, 156, 106253. [CrossRef]

102. Chen, B.; Jia, Y.; Zhang, M.; Li, X.; Yang, J.; Zhang, X. Facile Modification of Sepiolite and Its Application in Superhydrophobic Coatings. Appl. Clay Sci. 2019, 174, 1-9. [CrossRef]

103. Isaji, S.; Kojima, Y. Application of Copper Monoethanolamine Solutions as Primers for Semitransparent Exterior Wood Stains. Eur. J. Wood Wood Prod. 2017, 75, 305-314. [CrossRef]

104. Yang, Y.; Shan, L.; Shen, H.; Qiu, J. Manufacturing of Robust Superhydrophobic Wood Surfaces Based on PEG-Functionalized SiO2/PVA/PAA/Fluoropolymer Hybrid Transparent Coating. Prog. Org. Coat. 2021, 154, 106186. [CrossRef]

105. Lozhechnikova, A.; Bellanger, H.; Michen, B.; Burgert, I.; Österberg, M. Surfactant-Free Carnauba Wax Dispersion and Its Use for Layer-by-Layer Assembled Protective Surface Coatings on Wood. Appl. Surf. Sci. 2017, 396, 1273-1281. [CrossRef]

106. Lu, P.; Yun, H.; Zhang, W.; Tu, D.; Hu, C.; Cherdchim, B. A Facile Method of Superhydrophobic Coating on Rubberwood to Improve Its Anti-Mildew Performance. BioResources 2019, 14, 7111-7121. [CrossRef]

107. Kong, L.; Kong, X.; Ji, Z.; Wang, X.; Zhang, X. Large-Scale Fabrication of a Robust Superhydrophobic Thermal Energy Storage Sprayable Coating Based on Polymer Nanotubes. ACS Appl. Mater. Interfaces 2020, 12, 49694-49704. [CrossRef] [PubMed]

108. Janesch, J.; Czabany, I.; Hansmann, C.; Mautner, A.; Rosenau, T.; Gindl-Altmutter, W. Transparent Layer-by-Layer Coatings Based on Biopolymers and $\mathrm{CeO}_{2}$ to Protect Wood from UV Light. Prog. Org. Coat. 2020, 138, 105409. [CrossRef]

109. Weththimuni, M.L.; Capsoni, D.; Malagodi, M.; Licchelli, M. Improving Wood Resistance to Decay by Nanostructured ZnO-Based Treatments. J. Nanomater. 2019, 2019, 6715756. [CrossRef]

110. Tu, K.; Wang, X.; Kong, L.; Guan, H. Facile Preparation of Mechanically Durable, Self-Healing and Multifunctional Superhydrophobic Surfaces on Solid Wood. Mater. Des. 2018, 140, 30-36. [CrossRef]

111. Yang, R.; Zuo, S.; Song, B.; Mao, H.; Huang, Z.; Wu, Y.; Cai, L.; Ge, S.; Lian, H.; Xia, C. Hollow Mesoporous Microspheres Coating for Super-Hydrophobicity Wood with High Thermostability and Abrasion Performance. Polymers 2020, 12, 2856. [CrossRef] [PubMed] 
112. Liu, W.; Hu, C.; Zhang, W.; Liu, Z.; Shu, J.; Gu, J. Modification of Birch Wood Surface with Silane Coupling Agents for Adhesion Improvement of UV-Curable Ink. Prog. Org. Coat. 2020, 148, 105833. [CrossRef]

113. Yue, D.; Feng, Q.; Huang, X.; Zhang, X.; Chen, H. In Situ Fabrication of a Superhydrophobic ORMOSIL Coating on Wood by an Ammonia-HMDS Vapor Treatment. Coatings 2019, 9, 556. [CrossRef]

114. Shah, S.M.; Zulfiqar, U.; Hussain, S.Z.; Ahmad, I.; Habib-ur-Rehman; Hussain, I.; Subhani, T. A Durable Superhydrophobic Coating for the Protection of Wood Materials. Mater. Lett. 2017, 203, 17-20. [CrossRef]

115. Ou, J.; Zhao, G.; Wang, F.; Li, W.; Lei, S.; Fang, X.; Siddiqui, A.R.; Xia, Y.; Amirfazli, A. Durable Superhydrophobic Wood via One-Step Immersion in Composite Silane Solution. ACS Omega 2021, 6, 7266-7274. [CrossRef] [PubMed]

116. Jia, S.; Lu, Y.; Luo, S.; Qing, Y.; Wu, Y.; Parkin, I.P. Thermally-Induced All-Damage-Healable Superhydrophobic Surface with Photocatalytic Performance from Hierarchical BiOCl. Chem. Eng. J. 2019, 366, 439-448. [CrossRef]

117. Jia, S.; Liu, M.; Wu, Y.; Luo, S.; Qing, Y.; Chen, H. Facile and Scalable Preparation of Highly Wear-Resistance Superhydrophobic Surface on Wood Substrates Using Silica Nanoparticles Modified by VTES. Appl. Surf. Sci. 2016, 386, 115-124. [CrossRef]

118. Jia, S.; Chen, H.; Luo, S.; Qing, Y.; Deng, S.; Yan, N.; Wu, Y. One-Step Approach to Prepare Superhydrophobic Wood with Enhanced Mechanical and Chemical Durability: Driving of Alkali. Appl. Surf. Sci. 2018, 455, 115-122. [CrossRef]

119. Xing, Y.; Xue, Y.; Song, J.; Sun, Y.; Huang, L.; Liu, X.; Sun, J. Superhydrophobic Coatings on Wood Substrate for Self-Cleaning and EMI Shielding. Appl. Surf. Sci. 2018, 436, 865-872. [CrossRef]

120. Wang, Y.; Yan, W.; Frey, M.; Vidiella del Blanco, M.; Schubert, M.; Adobes-Vidal, M.; Cabane, E. Liquid-Like SiO 2 -g-PDMS Coatings on Wood Surfaces with Underwater Durability, Antifouling, Antismudge, and Self-Healing Properties. Adv. Sustain. Syst. 2019, 3, 1800070. [CrossRef]

121. Yao, Q.; Wang, C.; Fan, B.; Wang, H.; Sun, Q.; Jin, C.; Zhang, H. One-Step Solvothermal Deposition of ZnO Nanorod Arrays on a Wood Surface for Robust Superamphiphobic Performance and Superior Ultraviolet Resistance. Sci. Rep. 2016, 6, 35505. [CrossRef]

122. Kong, L.; Tu, K.; Guan, H.; Wang, X. Growth of High-Density ZnO Nanorods on Wood with Enhanced Photostability, Flame Retardancy and Water Repellency. Appl. Surf. Sci. 2017, 407, 479-484. [CrossRef]

123. Bao, W.; Zhang, M.; Jia, Z.; Jiao, Y.; Cai, L.; Liang, D.; Li, J. Cu Thin Films on Wood Surface for Robust Superhydrophobicity by Magnetron Sputtering Treatment with Perfluorocarboxylic Acid. Eur. J. Wood Wood Prod. 2019, 77, 115-123. [CrossRef]

124. Gao, J.; Lin, W.; Lin, S.; Zhang, X.; Yang, W.; Li, R. Environment-Friendly and Two-Component Method for Fabrication of Highly Hydrophobic Wood Using Poly(Methylhydrogen)Siloxane. Polymers 2021, 13, 124. [CrossRef] [PubMed]

125. Lu, X.; Hu, Y. Layer-by-Layer Deposition of $\mathrm{TiO}_{2}$ Nanoparticles in the Wood Surface and Its Superhydrophobic Performance. BioResources 2016, 11, 4605-4620. [CrossRef]

126. Zhang, X.; Xiao, F.; Feng, Q.; Zheng, J.; Chen, C.; Chen, H.; Yang, W. Preparation of $\mathrm{SiO}_{2}$ Nanoparticles with Adjustable Size for Fabrication of $\mathrm{SiO}_{2}$ /PMHS ORMOSIL Superhydrophobic Surface on Cellulose-Based Substrates. Prog. Org. Coat. 2020, 138, 105384. [CrossRef]

127. Guo, H.; Fuchs, P.; Casdorff, K.; Michen, B.; Chanana, M.; Hagendorfer, H.; Romanyuk, Y.E.; Burgert, I. Bio-Inspired Superhydrophobic and Omniphobic Wood Surfaces. Adv. Mater. Interfaces 2017, 4, 1600289. [CrossRef]

128. Yue, D.; Lin, S.; Cao, M.; Lin, W.; Zhang, X. Fabrication of Transparent and Durable Superhydrophobic Polysiloxane/SiO2 Coating on the Wood Surface. Cellulose 2021, 28, 3745-3758. [CrossRef]

129. Pandit, S.K.; Tudu, B.K.; Mishra, I.M.; Kumar, A. Development of Stain Resistant, Superhydrophobic and Self-Cleaning Coating on Wood Surface. Prog. Org. Coat. 2020, 139, 105453. [CrossRef]

130. Xia, M.; Yang, T.; Chen, S.; Yuan, G. Fabrication of Superhydrophobic Eucalyptus Wood Surface with Self-Cleaning Performance in Air and Oil Environment and High Durability. Colloids Interface Sci. Commun. 2020, 36, 100264. [CrossRef]

131. Kumar, A.; Tudu, B.K.; Pandit, S.K. Development of Novel Anti-wetting Coating on Cellulosic Surface Using Low Carbon Butyric Acid. Cellulose 2021, 28, 4825-4834. [CrossRef]

132. Tu, K.; Kong, L.; Wang, X.; Liu, J. Semitransparent, Durable Superhydrophobic Polydimethylsiloxane/SiO2 Nanocomposite Coatings on Varnished Wood. Holzforschung 2016, 70, 1039-1045. [CrossRef]

133. Wang, J.; Lu, Y.; Chu, Q.; Ma, C.; Cai, L.; Shen, Z.; Chen, H. Facile Construction of Superhydrophobic Surfaces by Coating Fluoroalkylsilane/Silica Composite on a Modified Hierarchical Structure of Wood. Polymers 2020, 12, 813. [CrossRef] [PubMed]

134. Guo, B.; Liu, Y.; Zhang, Q.; Wang, F.; Wang, Q.; Liu, Y.; Li, J.; Yu, H. Efficient Flame-Retardant and Smoke-Suppression Properties of Mg-Al-Layered Double-Hydroxide Nanostructures on Wood Substrate. ACS Appl. Mater. Interfaces 2017, 9, $23039-23047$. [CrossRef]

135. Wang, K.; Dong, Y.; Zhang, W.; Zhang, S.; Li, J. Prearation of Stable Superhydrophobic Coatings on Wood Substrate Surfaces via Mussel-Inspired Polydopamine and Electroless Deposition Methods. Polymers 2017, 9, 218. [CrossRef] [PubMed]

136. Huang, J.; Lyu, S.; Fu, F.; Chang, H.; Wang, S. Preparation of Superhydrophobic Coating with Excellent Abrasion Resistance and Durability Using Nanofibrillated Cellulose. RSC Adv. 2016, 6, 106194-106200. [CrossRef]

137. Huang, J.; Lyu, S.; Fu, F.; Wu, Y.; Wang, S. Green Preparation of a Cellulose Nanocrystals/Polyvinyl Alcohol Composite Superhydrophobic Coating. RSC Adv. 2017, 7, 20152-20159. [CrossRef]

138. Huang, J.; Wang, S.; Lyu, S. Facile Preparation of a Robust and Durable Superhydrophobic Coating Using Biodegradable Lignin-Coated Cellulose Nanocrystal Particles. Materials 2017, 10, 1080. [CrossRef] 
139. Yang, Y.; Shen, H.; Qiu, J. Fabrication of Biomimetic Robust Self-Cleaning Superhydrophobic Wood with Canna-Leaf-like Micro/Nanostructure through Morph-Genetic Method Improved Water-, UV-, and Corrosion Resistance Properties. J. Mol. Struct. 2020, 1219, 128616. [CrossRef]

140. Yang, Y.; He, H.; Li, Y.; Qiu, J. Using Nanoimprint Lithography to Create Robust, Buoyant, Superhydrophobic $\mathrm{PVB} / \mathrm{SiO}{ }_{2} \mathrm{Coatings}$ on Wood Surfaces Inspired by Red Roses Petal. Sci. Rep. 2019, 9, 9961. [CrossRef] [PubMed]

141. Chen, Y.; Wang, H.; Yao, Q.; Fan, B.; Wang, C.; Xiong, Y.; Jin, C.; Sun, Q. Biomimetic Taro Leaf-like Films Decorated on Wood Surfaces Using Soft Lithography for Superparamagnetic and Superhydrophobic Performance. J. Mater. Sci. 2017, 52, 7428-7438. [CrossRef]

142. Gan, W.; Gao, L.; Zhang, W.; Li, J.; Zhan, X. Fabrication of Microwave Absorbing $\mathrm{CoFe}_{2} \mathrm{O}_{4}$ Coatings with Robust Superhydrophobicity on Natural Wood Surfaces. Ceram. Int. 2016, 42, 13199-13206. [CrossRef]

143. Wang, K.; Wang, Z.; Dong, Y.; Zhang, S.; Li, J. Coordination-Driven Controlled Assembly of Polyphenol-Metal Green Coating on Wood Micro-Grooved Surfaces: A Novel Approach to Stable Superhydrophobicity. Polymers 2017, 9, 347. [CrossRef] [PubMed]

144. Tang, T.; Fu, Y. Formation of Chitosan/Sodium Phytate/Nano-Fe $\mathrm{O}_{4}$ Magnetic Coatings on Wood Surfaces via Layer-by-Layer Self-Assembly. Coatings 2020, 10, 51. [CrossRef]

145. Uddin, M.; Kiviranta, K.; Suvanto, S.; Alvila, L.; Leskinen, J.; Lappalainen, R.; Haapala, A. Casein-Magnesium Composite as an Intumescent Fire Retardant Coating for Wood. Fire Saf. J. 2020, 112, 102943. [CrossRef]

146. Xie, H.; Lai, X.; Li, H.; Gao, J.; Zeng, X.; Huang, X.; Lin, X. A Highly Efficient Flame Retardant Nacre-Inspired Nanocoating with Ultrasensitive Fire-Warning and Self-Healing Capabilities. Chem. Eng. J. 2019, 369, 8-17. [CrossRef]

147. Sahin, H.T.; Mantanis, G.I. Colour Changes of Pine and Fir Wood Treated with Several Titanium and Zinc-Oxide Based Nanocompounds. Adv. For. Lett. 2016, 5, 17-23. [CrossRef]

148. Nair, S.; Nagarajappa, G.B.; Pandey, K.K. UV Stabilization of Wood by Nano Metal Oxides Dispersed in Propylene Glycol. J. Photochem. Photobiol. B Biol. 2018, 183, 1-10. [CrossRef]

149. Wang, Y.; Wu, X.; Wang, Y.; Tian, Y.; Mu, H.; Li, J. Hydrophobic and UV-Resistant Properties of Environmentally Friendly Nano-ZnO-Coated Wood. Holzforschung 2021, 75, 138-147. [CrossRef]

150. Qu, L.; Rahimi, S.; Qian, J.; He, L.; He, Z.; Yi, S. Preparation and Characterization of Hydrophobic Coatings on Wood Surfaces by a Sol-Gel Method and Post-Aging Heat Treatment. Polym. Degrad. Stab. 2021, 183, 109429. [CrossRef]

151. Kanokwijitsilp, T.; Traiperm, P.; Osotchan, T.; Srikhirin, T. Development of Abrasion Resistance $\mathrm{SiO}_{2} \mathrm{Nanocomposite}^{\mathrm{C}} \mathrm{Cating}$ for Teak Wood. Prog. Org. Coat. 2016, 93, 118-126. [CrossRef]

152. Fu, Y.; Liu, X.; Cheng, F.; Sun, J.; Qin, Z. Modification of the Wood Surface Properties of Tsoongiodendron Odorum Chun with Silicon Dioxide by a Sol-Gel Method. BioResources 2016, 11, 10273-10285. [CrossRef]

153. Xuan, L.; Fu, Y.; Liu, Z.; Wei, P.; Wu, L. Hydrophobicity and Photocatalytic Activity of a Wood Surface Coated with a Fe ${ }^{3+}$-Doped $\mathrm{SiO}_{2} / \mathrm{TiO}_{2}$ Film. Materials 2018, 11, 2594. [CrossRef]

154. Liu, Z.; Xuan, L.; Fu, Y. Aging Resistance and Photocatalytic Activity of a Wood Surface Coated with a $\mathrm{Zr}^{4+}-\mathrm{Doped} \mathrm{SiO}_{2} / \mathrm{TiO}_{2}$ Film. BioResources 2020, 15, 6404-6419. [CrossRef]

155. Qian, T.; Dang, B.; Chen, Y.; Jin, C.; Qian, J.; Sun, Q. Fabrication of Magnetic Phase Change $\mathrm{N}_{-} \mathrm{Eicosane}_{\mathrm{C}} \mathrm{Fe}_{3} \mathrm{O}_{4} / \mathrm{SiO}_{2}$ Microcapsules on Wood Surface via Sol-Gel Method. J. Alloys Compd. 2019, 772, 871-876. [CrossRef]

156. Guo, H.; Fuchs, P.; Cabane, E.; Michen, B.; Hagendorfer, H.; Romanyuk, Y.E.; Burgert, I. UV-Protection of Wood Surfaces by Controlled Morphology Fine-Tuning of ZnO Nanostructures. Holzforschung 2016, 70, 699-708. [CrossRef]

157. Qing, Y.; Liu, M.; Wu, Y.; Jia, S.; Wang, S.; Li, X. Investigation on Stability and Moisture Absorption of Superhydrophobic Wood under Alternating Humidity and Temperature Conditions. Results Phys. 2017, 7, 1705-1711. [CrossRef]

158. Pori, P.; Vilčnik, A.; Petrič, M.; Sever Škapin, A.; Mihelčič, M.; Šurca Vuk, A.; Novak, U.; Orel, B. Structural Studies of TiO 2 /Wood Coatings Prepared by Hydrothermal Deposition of Rutile Particles from $\mathrm{TiCl}_{4}$ Aqueous Solutions on Spruce (Picea Abies) Wood. Appl. Surf. Sci. 2016, 372, 125-138. [CrossRef]

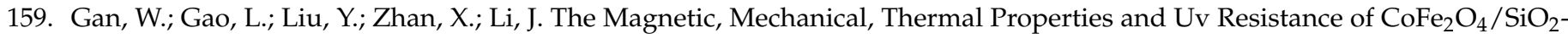
Coated Film on Wood. J. Wood Chem. Technol. 2016, 36, 94-104. [CrossRef]

160. Sun, M.; Song, K. Low Temperature Hydrothermal Fabrication of Tungsten Trioxide on the Surface of Wood with Photochromic and Superhydrophobic Properties. BioResources 2018, 13, 1075-1087. [CrossRef]

161. Sun, M.; Song, K. Effect of Tungsten Trioxide Nanosheets Prepared under Low-Energy State on Wood Surface Modification. BioResources 2019, 14, 9146-9158. [CrossRef]

162. Hui, B.; Li, G.; Li, J.; Via, B.K. Hydrothermal Deposition and Photoresponsive Properties of WO 3 Thin Films on Wood Surfaces Using Ethanol as an Assistant Agent. J. Taiwan Inst. Chem. Eng. 2016, 64, 336-342. [CrossRef]

163. Hui, B.; Li, J. Low-Temperature Synthesis of Hierarchical Flower-like Hexagonal Molybdenum Trioxide Films on Wood Surfaces and Their Light-Driven Molecular Responses. J. Mater. Sci. 2016, 51, 10926-10934. [CrossRef]

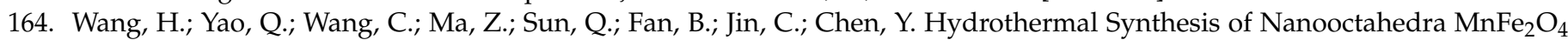
onto the Wood Surface with Soft Magnetism, Fire Resistance and Electromagnetic Wave Absorption. Nanomaterials 2017, 7, 118. [CrossRef] [PubMed]

165. Wang, H.; Yao, Q.; Wang, C.; Fan, B.; Sun, Q.; Jin, C.; Xiong, Y.; Chen, Y. A Simple, One-Step Hydrothermal Approach to Durable and Robust Superparamagnetic, Superhydrophobic and Electromagnetic Wave-Absorbing Wood. Sci. Rep. 2016, 6, 35549. [CrossRef] [PubMed] 
166. Belykh, S.; Novoselova, J.; Novoselov, D. Fire Retardant Coating for Wood Using Resource-Saving Technologies. In International Scientific Conference Energy Management of Municipal Facilities and Sustainable Energy Technologies EMMFT 2018 Volume 1; Murgul, V., Pasetti, M., Eds.; Springer: Singapore, 2020; pp. 673-681, ISBN 978-3-030-19756-8.

167. Pan, Y.; Yin, D.; Surigala, S.; Hao, Y.; Xing, D.; Hao, S.; Yu, X.; Yu, H.; Huang, J. Performance and Preparation of the Electroless Ni Wood-Based Composites. BioResources 2020, 15, 7517-7531. [CrossRef]

168. Pan, Y.; Yin, D.; Yu, X.; Hao, N.; Huang, J. Multilayer-Structured Wood Electroless Cu-Ni Composite Coatings for Electromagnetic Interference Shielding. Coatings 2020, 10, 740. [CrossRef]

169. Pan, Y.F.; Guo, Z.Q.; Guo, T.C.; Wang, X.; Huang, J.T. The Preparation, Characterization, and Influence of Multiple Electroless Nickel-Phosphorus (Ni-P) Hollow Composite Coatings on Micro-Nano Cellulose Fibers. Surf. Coat. Technol. 2016, 298, 33-38. [CrossRef]

170. Wang, N.; Wang, Q.; Xu, S.; Qu, L.; Shi, Z. Robust Superhydrophobic Wood Surfaces with Mechanical Durability. Colloids Surfaces A Physicochem. Eng. Asp. 2021, 608, 125624. [CrossRef]

171. Łukawski, D.; Lekawa-Raus, A.; Lisiecki, F.; Koziol, K.; Dudkowiak, A. Towards the Development of Superhydrophobic Carbon Nanomaterial Coatings on Wood. Prog. Org. Coat. 2018, 125, 23-31. [CrossRef]

172. Yuan, B.; Ji, X.; Nguyen, T.T.; Huang, Z.; Guo, M. UV Protection of Wood Surfaces by Graphitic Carbon Nitride Nanosheets. Appl. Surf. Sci. 2019, 467-468, 1070-1075. [CrossRef]

173. Liu, J.; Kutty, R.G.; Zheng, Q.; Eswariah, V.; Sreejith, S.; Liu, Z. Hexagonal Boron Nitride Nanosheets as High-Performance Binder-Free Fire-Resistant Wood Coatings. Small 2017, 13, 1-6. [CrossRef] [PubMed]

174. Chu, P.K.; Chen, J.Y.; Wang, L.P.; Huang, N. Plasma-Surface Modification of Biomaterials. Mater. Sci. Eng. R Rep. 2002, 36, 143-206. [CrossRef]

175. Petrič, M. Surface Modification of Wood: A Critical Review. Rev. Adhes. Adhes. 2013, 1, 216-247. [CrossRef]

176. Haase, J.G.; Leung, L.H.; Evans, P.D. Plasma Pre-Treatments to Improve the Weather Resistance of Polyurethane Coatings on Black Spruce Wood. Coatings 2019, 9, 8. [CrossRef]

177. Žigon, J.; Pavlič, M.; Kibleur, P.; Van Den Bulcke, J.; Petrič, M.; Van Acker, J.; Dahle, S. Treatment of Wood with Atmospheric Plasma Discharge: Study of the Treatment Process, Dynamic Wettability and Interactions with a Waterborne Coating. Holzforschung 2020, 75, 603-613. [CrossRef]

178. Žigon, J.; Petrič, M.; Dahle, S. Artificially Aged Spruce and Beech Wood Surfaces Reactivated Using FE-DBD Atmospheric Plasma. Holzforschung 2019, 73, 1069-1081. [CrossRef]

179. de Cademartori, P.H.G.; Nisgoski, S.; Magalhães, W.L.E.; de Muniz, G.I.B. Surface Wettability of Brazilian Tropical Wood Flooring Treated with He Plasma. Maderas Cienc. Tecnol. 2016, 18, 715-722. [CrossRef]

180. Žigon, J.; Kovač, J.; Zaplotnik, R.; Saražin, J.; Šernek, M.; Petrič, M.; Dahle, S. Enhancement of Strength of Adhesive Bond between Wood and Metal Using Atmospheric Plasma Treatment. Cellulose 2020, 27, 6411-6424. [CrossRef]

181. Ivanov, I.; Dineff, P. Plasma-Aided Surface Finishing for Flame Retardation of Wood Through the Use of Surfactants. Mach. Technol. Mater. 2016, 10, 49-52.

182. Novák, I.; Sedliačik, J.; Kleinová, A.; Matyasovsky, J. Oak Wood Pre-Treated by Cold Plasma. Ann. Warsaw Univ. Life Sci. SGGW For. Wood Technol. 2018, 104, 163-168.

183. Novák, I.; Sedliačik, J.; Kleinova, A.; Mstyasovsky, J.; Jurkovič, P. Discharge Plasma Treatment of Wood Surfaces. Ann. Warsaw Univ. Life Sci. SGGW For. Wood Technol. 2018, 104, 169-173.

184. Novák, I.; Sedliačik, J.; Chodák, I.; Mičusik, M.; Matyasovsky, J.; Jurkovič, P. Modification of Wood by Radio-Frequency Discharge Plasma. Ann. Warsaw Univ. Life Sci. SGGW For. Wood Technol. 2019, 105, 85-90. [CrossRef]

185. Novák, I.; Sedliačik, J.; Krystofiak, T.; Lis, B.; Popelka, A.; Kleinová, A.; Matyašovský, J.; Jurkovič, P.; Bekhta, P. Study of Wood Surface Pre-Treatment by Radio-Frequency Discharge Plasma. Drewno 2019, 62, 81-91. [CrossRef]

186. Jablonsky, M.; Smatko, L.; Botkova, M.; Tino, R.; Slma, J. Modification of Wood Wettability (European Beech) by Diffuse Coplanar Surface Barrier Discharge Plasma. Cellul. Chem. Technol. 2016, 50, 41-48.

187. Tang, Z.; Xie, L.; Hess, D.W.; Breedveld, V. Fabrication of Amphiphobic Softwood and Hardwood by Treatment with NonFluorinated Chemicals. Wood Sci. Technol. 2017, 51, 97-113. [CrossRef]

188. Žigon, J.; Petrič, M.; Dahle, S. Dielectric and Surface Properties of Wood Modified with NaCl Aqueous Solutions and Treated with FE-DBD Atmospheric Plasma. Eur. J. Wood Wood Prod. 2021, 79, 1117-1128. [CrossRef]

189. Žigon, J.; Dahle, S. Improvement of Plasma Treatment Efficiency of Wood and Coating Process by Sodium Chloride Aqueous Solutions. Pro Ligno 2019, 15, 260-267.

190. Peng, X.; Zhang, Z. Improvement of Paint Adhesion of Environmentally Friendly Paint Film on Wood Surface by Plasma Treatment. Prog. Org. Coat. 2019, 134, 255-263. [CrossRef]

191. Dahle, S.; Meuthen, J.; Gustus, R.; Prowald, A.; Viöl, W.; Maus-Friedrichs, W. Superhydrophilic Coating of Pine Wood by Plasma Functionalization of Self-Assembled Polystyrene Spheres. Coatings 2021, 11, 114. [CrossRef]

192. Gospodinova, D.N.; Dineff, P.D. Energy Efficiency of Atmospheric Pressure Plasma-Aided Porous Media Surface Finishing. IOP Conf. Ser. Mater. Sci. Eng. 2019, 618, 012019. [CrossRef]

193. Volokitin, G.; Skripnikova, N.; Volokitin, O.; Shekhovtsov, V.; Balobanov, P.; Pfuch, A. Modification of Wood Properties by Highly-Concentrated Plasma Flow. Key Eng. Mater. 2018, 781, 88-92. [CrossRef] 
194. Chen, W.; Zhou, X.; Zhang, X.; Bian, J.; Shi, S.; Nguyen, T.; Chen, M.; Wan, J. Fast Enhancement on Hydrophobicity of Poplar Wood Surface Using Low-Pressure Dielectric Barrier Discharges (DBD) Plasma. Appl. Surf. Sci. 2017, 407, 412-417. [CrossRef]

195. Wallenhorst, L.; Gurău, L.; Gellerich, A.; Militz, H.; Ohms, G.; Viöl, W. UV-Blocking Properties of Zn/ZnO Coatings on Wood Deposited by Cold Plasma Spraying at Atmospheric Pressure. Appl. Surf. Sci. 2018, 434, 1183-1192. [CrossRef]

196. Profili, J.; Levasseur, O.; Koronai, A.; Stafford, L.; Gherardi, N. Deposition of Nanocomposite Coatings on Wood Using Cold Discharges at Atmospheric Pressure. Surf. Coat. Technol. 2017, 309, 729-737. [CrossRef]

197. Tuominen, M.; Teisala, H.; Haapanen, J.; Mäkelä, J.M.; Honkanen, M.; Vippola, M.; Bardage, S.; Wålinder, M.E.P.; Swerin, A. Superamphiphobic Overhang Structured Coating on a Biobased Material. Appl. Surf. Sci. 2016, 389, 135-143. [CrossRef]

198. de Cademartori, P.H.G.; Stafford, L.; Blanchet, P.; Magalhães, W.L.E.; de Muniz, G.I.B. Enhancing the Water Repellency of Wood Surfaces by Atmospheric Pressure Cold Plasma Deposition of Fluorocarbon Film. RSC Adv. 2017, 7, 29159-29169. [CrossRef]

199. Levasseur, O.; Vlad, M.; Profili, J.; Gherardi, N.; Sarkissian, A.; Stafford, L. Deposition of Fluorocarbon Groups on Wood Surfaces Using the Jet of an Atmospheric-Pressure Dielectric Barrier Discharge. Wood Sci. Technol. 2017, 51, 1339-1352. [CrossRef]

200. Bigan, M.; Mutel, B. Cold Remote Plasma Modification of Wood: Optimization Process Using Experimental Design. Appl. Surf. Sci. 2018, 453, 423-435. [CrossRef]

201. Sohbatzadeh, F.; Shabannejad, A.; Ghasemi, M.; Mahmoudsani, Z. Deposition of Halogen-Free Flame Retardant and WaterRepellent Coatings on Firwood Surfaces Using the New Version of DBD. Prog. Org. Coat. 2021, 151, 106070. [CrossRef]

202. Chen, W.; Zhou, X.; Zhang, X.; Feizbakhshan, M.; Cao, Y.; Shi, S.; Nguyen, T.; Chen, M. Fast Formation of Hydrophobic Coating on Wood Surface via an Energy-Saving Dielectric Barrier Discharges Plasma. Prog. Org. Coat. 2018, 125, 128-136. [CrossRef]

203. Köhler, R.; Sauerbier, P.; Militz, H.; Viöl, W. Atmospheric Pressure Plasma Coating of Wood and MDF with Polyester Powder. Coatings 2017, 7, 171. [CrossRef]

204. Köhler, R.; Sauerbier, P.; Ohms, G.; Viöl, W.; Militz, H. Wood Protection through Plasma Powder Deposition-An Alternative Coating Process. Forests 2019, 10, 898. [CrossRef]

205. Jnido, G.; Ohms, G.; Viöl, W. One-Step Deposition of Polyester/ $\mathrm{TiO}_{2}$ Coatings by Atmospheric Pressure Plasma Jet on Wood Surfaces for UV and Moisture Protection. Coatings 2020, 10, 184. [CrossRef]

206. Gascón-Garrido, P.; Mainusch, N.; Militz, H.; Viöl, W.; Mai, C. Copper and Aluminium Deposition by Cold-Plasma Spray on Wood Surfaces: Effects on Natural Weathering Behaviour. Eur. J. Wood Wood Prod. 2017, 75, 315-324. [CrossRef]

207. Jnido, G.; Ohms, G.; Viöl, W. Deposition of Zinc Oxide Coatings on Wood Surfaces Using the Solution Precursor Plasma Spraying Process. Coatings 2021, 11, 183. [CrossRef]

208. Jnido, G.; Ohms, G.; Viöl, W. Deposition of $\mathrm{TiO}_{2}$ Thin Films on Wood Substrate by an Air Atmospheric Pressure Plasma Jet. Coatings 2019, 9, 441. [CrossRef]

209. Kettner, F.; Plaschkies, K.; Gerullis, S.; Pfuch, A.; Küzün, B. Raising the Permanent Adhesion of Coatings on Resinous Wood by APPCVD Promotion. Int. J. Adhes. Adhes. 2020, 102, 102642. [CrossRef]

210. Fernández-Costas, C.; Palanti, S.; Charpentier, J.P.; Sanromán, M.Á.; Moldes, D. A Sustainable Treatment for Wood Preservation: Enzymatic Grafting of Wood Extractives. ACS Sustain. Chem. Eng. 2017, 5, 7557-7567. [CrossRef]

211. Wang, Y.; Tang, Z.; Lu, S.; Zhang, M.; Liu, K.; Xiao, H.; Huang, L.; Chen, L.; Wu, H.; Ni, Y. Superhydrophobic Wood Grafted by Poly(2-(Perfluorooctyl)Ethyl Methacrylate) via ATRP with Self-Cleaning, Abrasion Resistance and Anti-Mold Properties. Holzforschung 2020, 74, 799-809. [CrossRef]

212. Sharma, G.; Kumar, A.; Naushad, M.; Al-Misned, F.A.; El-Serehy, H.A.; Ghfar, A.A.; Rai Sharma, K.; Si, C.; Stadler, F.J. Graft Copolymerization of Acrylonitrile and Ethyl Acrylate onto Pinus Roxburghii Wood Surface Enhanced Physicochemical Properties and Antibacterial Activity. J. Chem. 2020, 2020, 6285354. [CrossRef]

213. Filgueira, D.; Moldes, D.; Fuentealba, C.; García, D.E. Condensed Tannins from Pine Bark: A Novel Wood Surface Modifier Assisted by Laccase. Ind. Crops Prod. 2017, 103, 185-194. [CrossRef]

214. Song, L.; Zhang, X.F.; Wang, Z.; Bai, Y.; Feng, Y.; Yao, J. Metal-Ion Induced Surface Modification for Durable Hydrophobic Wood. Adv. Mater. Interfaces 2020, 7, 2001166. [CrossRef]

215. Pouzet, M.; Dubois, M.; Charlet, K.; Béakou, A. From Hydrophilic to Hydrophobic Wood Using Direct Fluorination: A Localized Treatment. Comptes Rendus Chim. 2018, 21, 800-807. [CrossRef]

216. Pouzet, M.; Dubois, M.; Charlet, K.; Béakou, A.; Leban, J.M.; Baba, M. Fluorination Renders the Wood Surface Hydrophobic without Any Loss of Physical and Mechanical Properties. Ind. Crops Prod. 2019, 133, 133-141. [CrossRef]

217. Pouzet, M.; Dubois, M.; Charlet, K.; Petit, E.; Béakou, A.; Dupont, C. Fluorination/Torrefaction Combination to Further Improve the Hydrophobicity of Wood. Macromol. Chem. Phys. 2019, 220, 1900041. [CrossRef]

218. Gabrič, M.V.; Boncina, T.; Humar, M.; Pohleven, F. Laccase Treatment of Norway Spruce Wood Surface Improves Resistance and Copper Fixation of Treated Wood. Drewno 2016, 59, 19-34. [CrossRef]

219. Kotlyarova, I.A.; Stepina, I.V. Decrease in Swelling Capacity of Pine Wood Modified with Aminoborates. IOP Conf. Ser. Mater. Sci. Eng. 2018, 463, 022007. [CrossRef]

220. James, R.M.S.; Md Tahir, P.; Hua, L.S.; Abdullah, U.H.; Uyup, M.K.A.; Mohd Yusof, N.; Johari, I. Finishing Performance of Acacia mangium Wood Surface-Treated with Methanol. J. Adhes. 2020, 1-20. [CrossRef]

221. Barkai, H.; Elabed, S.; Sadiki, M.; Boutahari, S.; Mounyr, B.; Omar, E.F. The Effect of Cellulase Treatment Time on the Cedar Wood Surface Physicochemical Properties. Am. J. Adv. Sci. Res. 2016, 3, 296-304. 
222. Barkai, H.; Soumya, E.; Sadiki, M.; Mounyr, B.; Ibnsouda, K.S. Impact of Enzymatic Treatment on Wood Surface Free Energy: Contact Angle Analysis. J. Adhes. Sci. Technol. 2017, 31, 726-734. [CrossRef]

223. Lin, W.; Huang, Y.; Li, J.; Liu, Z.; Yang, W.; Li, R.; Chen, H.; Zhang, X. Preparation of Highly Hydrophobic and Anti-Fouling Wood Using Poly(Methylhydrogen)Siloxane. Cellulose 2018, 25, 7341-7353. [CrossRef]

224. Papadopoulos, A.N.; Foti, D.; Kyzas, G.Z. Sorption Behavior of Water Vapor of Wood Treated by Chitosan Polymer. Eur. J. Wood Wood Prod. 2020, 78, 483-491. [CrossRef]

225. Reinprecht, L.; Vidholdová, Z. The Impact of a $\mathrm{CO}_{2}$ Laser on the Adhesion and Mold Resistance of a Synthetic Polymer Layer on a Wood Surface. Forests 2021, 12, 242. [CrossRef]

226. Vidholdová, Z.; Reinprecht, L.; Igaz, R. The Impact of Laser Surface Modification of Beech Wood on Its Color and Occurrence of Molds. BioResources 2017, 12, 4177-4186. [CrossRef]

227. Kúdela, J.; Reinprecht, L.; Vidholdová, Z.; Andrejko, M. Surface Properties of Beech Wood Modified by $\mathrm{CO}_{2}$ Laser. Acta Fac. Xylologiae Zvolen 2019, 61, 5-18. [CrossRef]

228. Kymäläinen, M.; Hautamäki, S.; Lillqvist, K.; Segerholm, K.; Rautkari, L. Surface Modification of Solid Wood by Charring. J. Mater. Sci. 2017, 52, 6111-6119. [CrossRef]

229. Kymäläinen, M.; Turunen, H.; Cermák, P.; Hautamäki, S.; Rautkari, L. Sorption-Related Characteristics of Surface Charred Spruce Wood. Materials 2018, 11, 2083. [CrossRef]

230. Čermák, P.; Dejmal, A.; Paschová, Z.; Kymäläinen, M.; Dömény, J.; Brabec, M.; Hess, D.; Rautkari, L. One-Sided Surface Charring of Beech Wood. J. Mater. Sci. 2019, 54, 9497-9506. [CrossRef]

231. Akcay, C.; Karal Saygin, İ.; Tascioglu, C. Decay Resistance of Carbonized Wood Surfaces. Düzce Univ. J. Sci. Technol. 2020, 8, 746-753. [CrossRef]

232. Triquet, J.; Blanchet, P.; Landry, V. Chemical Surface Densification of Hardwood through Lateral Monomer Impregnation and in Situ Electron Beam Polymerization, Part I: Density Profile and Surface Hardness of Three Hardwood Species. J. Mater. Sci. 2021, 56, 11309-11323. [CrossRef]

233. Wu, J.; Fan, Q.; Wang, Q.; Guo, Q.; Tu, D.; Chen, C.; Xiao, Y.; Ou, R. Improved Performance of Poplar Wood by an EnvironmentallyFriendly Process Combining Surface Impregnation of a Reactive Waterborne Acrylic Resin and Unilateral Surface Densification. J. Clean. Prod. 2020, 261, 121022. [CrossRef]

234. Han, L. Reduction of Set-Recovery of Surface-Densified Scots Pine by Furfuryl Alcohol. Master's Thesis, Luleå University of Technology, Luleå, Sweden, 2019.

235. Neyses, B.; Rautkari, L.; Yamamoto, A.; Sandberg, D. Pre-Treatment with Sodium Silicate, Sodium Hydroxide, Ionic Liquids or Methacrylate Resin to Reduce the Set-Recovery and Increase the Hardness of Surface-Densified Scots Pine. iForest 2017, 10, 857-864. [CrossRef]

236. Lafond, C.; Blanchet, P.; Landry, V.; Galimard, P.; Ménard, S. The Effects of Acrylate Impregnation of Black Spruce Timber as Connectors Strength. BioResources 2016, 11, 1753-1764. [CrossRef]

237. Dagher, R.; Landry, V.; Stevanovic, T. Contribution to Understanding the Color Development on Wood Surfaces Treated with Iron Salts by a Combination of Analytical Methods. J. Wood Chem. Technol. 2020, 40, 223-234. [CrossRef]

238. Harandi, D.; González-Benito, J.; Olmos, D. Consolidation of Fir Wood by Poly(Vinyl Butyral-Co-Vinyl Alcohol-Co-Vinyl Acetate) Treatment: Study of Surface and Mechanical Characteristics. Polymers 2020, 12, 1039. [CrossRef] [PubMed]

239. Kumar, A.; Ryparová, P.; Škapin, A.S.; Humar, M.; Pavlič, M.; Tywoniak, J.; Hajek, P.; Žigon, J.; Petrič, M. Influence of Surface Modification of Wood with Octadecyltrichlorosilane on Its Dimensional Stability and Resistance against Coniophora Puteana and Molds. Cellulose 2016, 23, 3249-3263. [CrossRef]

240. Kumar, A.; Richter, J.; Tywoniak, J.; Hajek, P.; Adamopoulos, S.; Šegedin, U.; Petric, M. Surface Modification of Norway Spruce Wood by Octadecyltrichlorosilane (OTS) Nanosol by Dipping and Water Vapour Diffusion Properties of the OTS-Modified Wood. Holzforschung 2017, 72, 45-56. [CrossRef]

241. He, S.; Wu, W.; Zhang, M.; Qu, H.; Xu, J. Synergistic Effect of Silica Sol and $\mathrm{K}_{2} \mathrm{CO}_{3}$ on Flame-Retardant and Thermal Properties of Wood. J. Therm. Anal. Calorim. 2017, 128, 825-832. [CrossRef]

242. Zhu, X.; Liu, Y.; Dong, N.; Li, Z. Fabrication and Characterization of Reversible Thermochromic Wood Veneers. Sci. Rep. 2017, 7, 16933. [CrossRef] [PubMed]

243. Pokrovskaya, E. Fire-Protection of Wooden Structures by Modification in a Thin Surface Layer. In Proceedings of the MATEC Web of Conferences 251: Integration, Partnership and Innovation in Construction Science and Education (IPICSE-2018), Moscow, Russia, 14-16 November 2018; pp. 1-5. [CrossRef]

244. Kim, I.; Karlsson, O.; Myronycheva, O.; Jones, D.; Sandberg, D. Methacrylic Resin for Protection of Wood from Discoloration by Mould Growth and Weathering. BioResources 2020, 15, 7018-7033. [CrossRef]

245. Hassan, B.; Soumya, E.; Moulay, S.; Mounyr, B.; Hajar, M.; Koraichi, I.S. Evaluation of Hydrophobic-Hydrophilic Properties and Anti-Adhesive Potential of the Treated Cedar Wood by Two Essential Oil Components Against Bioadhesion of Penicillium Expansum Spores. J. Appl. Sci. 2016, 16, 372-379. [CrossRef]

246. Yves, K.G.; Chen, T.; Aladejana, J.T.; Wu, Z.; Xie, Y. Preparation, Test, and Analysis of a Novel Aluminosilicate-Based Antimildew Agent Applied on the Microporous Structure of Wood. ACS Omega 2020, 5, 8784-8793. [CrossRef]

247. Qian, J.; He, Z.; Li, J.; Wang, Z.; Qu, L.; Yi, S. Effect of Wax and Dimethyl Silicone Oil Pretreatment on Wood Hygroscopicity, Chemical Components, and Dimensional Stability. BioResources 2019, 13, 6265-6279. [CrossRef] 
248. European Comitee for Standardization. Eurocode 5: Design of Timber Structures—Part 1-2: General—Structural Fire Design; European Union: Brussels, Belgium, 2004; Volume 1, p. 66.

249. White, R.H. Analytical Methods for Determining Fire Resistance of Timber Members. In SFPE Handbook of Fire Protection Engineering, 4th ed.; SFPE: Quincy, MA, USA, 2008; Chapter 13; pp. 4.346-4.366, ISBN 9781493925650.

250. Hao, J.; Chow, W.K. A Brief Review of Intumescent Fire Retardant Coatings. Archit. Sci. Rev. 2003, 46, 89-95. [CrossRef]

251. White, R.H. Oxygen Index Evaluation Of Fire-Retardant-Treated Wood. Wood Sci. 1978, 12, 113-122.

252. Östman, B.; Voss, A.; Hughes, A.; Hovde, P.J.; Grexa, O. Durability of Fire Retardant Treated Wood Products at Humid and Exterior Conditions Review of Literature. Fire Mater. 2001, 25, 95-104. [CrossRef]

253. American Wood Protection Association. Information for Building Code Officials. Available online: https://awpa.com/info/ technical/codes (accessed on 5 August 2021).

254. Blanchette, R.A.; Nilsson, T.; Daniel, G.; Abad, A. Biological Degradation of Wood. In Archaeological Wood: Properties, Chemistry, and Preservation; Rowell, R.M., Barbour, R.J., Eds.; American Chemical Society: Washington, DC, USA, 1990; Volume 225, pp. 141-174, ISBN 9780841224070.

255. Meyer, L.; Brischke, C. Fungal Decay at Different Moisture Levels of Selected European-Grown Wood Species. Int. Biodeterior. Biodegrad. 2015, 103, 23-29. [CrossRef]

256. Rowell, R.M.; Banks, W.B. Water Repellency and Dimensional Stability of Wood; U.S. Department of Agriculture Forest Products Laboratory: Madison, WI, USA, 1985; p. 24. [CrossRef]

257. Feng, L.; Li, S.; Li, Y. Super-Hydrophobic Surfaces: From Natural to Artificial. Adv. Mater. 2002, 14, 1857-1860. [CrossRef]

258. Xiang, S.; Liu, W. Self-Healing Superhydrophobic Surfaces: Healing Principles and Applications. Adv. Mater. Interfaces 2021, 8 , 2100247. [CrossRef]

259. Klüppel, A.; Cragg, S.M.; Militz, H.; Mai, C. Resistance of Modified Wood to Marine Borers. Int. Biodeterior. Biodegrad. 2015, 104, 8-14. [CrossRef]

260. Johnson, B.R. A Look at Creosote vs. Chromated Copper Arsenate Salts as Wood Preservatives for the Marine Environment. Ind. Eng. Chem. Prod. Res. Dev. 1982, 21, 704-705. [CrossRef]

261. Ahmed, S. Safety Aspects of Coatings. In Polymer Science: Coatings E Adhesives; NISCAIR: New Delhi, India, $2007 ;$ p. 15.

262. Auffan, M.; Masion, A.; Labille, J.; Diot, M.A.; Liu, W.; Olivi, L.; Proux, O.; Ziarelli, F.; Chaurand, P.; Geantet, C.; et al. Long-Term Aging of a $\mathrm{CeO}_{2}$ Based Nanocomposite Used for Wood Protection. Environ. Pollut. 2014, 188, 1-7. [CrossRef]

263. Ng, C.T.; Yong, L.Q.; Hande, M.P.; Ong, C.N.; Yu, L.E.; Bay, B.H.; Baeg, G.H. Zinc Oxide Nanoparticles Exhibit Cytotoxicity and Genotoxicity through Oxidative Stress Responses in Human Lung Fibroblasts and Drosophila Melanogaster. Int. J. Nanomed. 2017, 12, 1621-1637. [CrossRef] [PubMed]

264. Schrand, A.M.; Rahman, M.F.; Hussain, S.M.; Schlager, J.J.; Smith, D.A.; Syed, A.F. Metal-Based Nanoparticles and Their Toxicity Assessment. Wiley Interdiscip. Rev. Nanomed. Nanobiotechnol. 2010, 2, 544-568. [CrossRef]

265. Tortella, G.R.; Rubilar, O.; Durán, N.; Diez, M.C.; Martínez, M.; Parada, J.; Seabra, A.B. Silver Nanoparticles: Toxicity in Model Organisms as an Overview of Its Hazard for Human Health and the Environment. J. Hazard. Mater. 2020, 390, 121974. [CrossRef] [PubMed]

266. Maurer-Jones, M.A.; Gunsolus, I.L.; Murphy, C.J.; Haynes, C.L. Toxicity of Engineered Nanoparticles in the Environment. Anal. Chem. 2013, 85, 3036-3049. [CrossRef]

267. Sajid, M.; Ilyas, M.; Basheer, C.; Tariq, M.; Daud, M.; Baig, N.; Shehzad, F. Impact of Nanoparticles on Human and Environment: Review of Toxicity Factors, Exposures, Control Strategies, and Future Prospects. Environ. Sci. Pollut. Res. Vol. 2015, 22, 4122-4143. [CrossRef] [PubMed]

268. Ameh, T.; Sayes, C.M. The Potential Exposure and Hazards of Copper Nanoparticles: A Review. Environ. Toxicol. Pharmacol. 2019, 71, 103220. [CrossRef] [PubMed]

269. Baranowska-wójcik, E.; Szwajgier, D.; Oleszczuk, P.; Winiarska-mieczan, A. Effects of Titanium Dioxide Nanoparticles Exposure on Human Health-A Review. Biol. Trace Elem. Res. 2020, 193, 118-129. [CrossRef]

270. Remzova, M.; Zouzelka, R.; Brzicova, T.; Vrbova, K.; Pinkas, D.; Topinka, J.; Rathousky, J.; Pavel, R. Toxicity of TiO 2 , ZnO, and $\mathrm{SiO}_{2}$ Nanoparticles in Human Lung Cells: Safe-by-Design Development of Construction Materials. Nanomaterials 2019, 9, 968. [CrossRef]

271. Abdel-Latif, H.M.R.; Shukry, M.; El Euony, O.I.; Soliman, M.M.; Noreldin, A.E.; Ghetas, H.A.; Dawood, M.A.O.; Khallaf, M.A. Hazardous Effects of $\mathrm{SiO}_{2}$ Nanoparticles on Liver and Kidney Functions, Histopathology Characteristics, and Transcriptomic Responses in Nile Tilapia (Oreochromis niloticus) Juveniles. Biology 2021, 10, 183. [CrossRef]

272. Kumar, N.; Chandan, N.K.; Wakchaure, G.C.; Singh, N.P. Synergistic Effect of Zinc Nanoparticles and Temperature on Acute Toxicity with Response to Biochemical Markers and Histopathological Attributes in Fish. Comp. Biochem. Physiol. Part-C Toxicol. Pharmacol. 2020, 229, 108678. [CrossRef]

273. Yang, J.; Cao, W.; Rui, Y. Interactions between Nanoparticles and Plants: Phytotoxicity and Defense Mechanisms. J. Plant Interact. 2017, 12, 158-169. [CrossRef]

274. Tripathi, D.K.; Shweta; Singh, S.; Singh, S.; Pandey, R.; Singh, V.P.; Sharma, N.C.; Prasad, S.M.; Dubey, N.K.; Chauhan, D.K. An Overview on Manufactured Nanoparticles in Plants: Uptake, Translocation, Accumulation and Phytotoxicity. Plant Physiol. Biochem. 2017, 110, 2-12. [CrossRef] 
275. Endes, C.; Espinosa, S.C.; Mueller, S.; Foster, E.J.; Fink, A.P.; Rutishauser, B.R.; Weder, C. A Critical Review of the Current Knowledge Regarding the Biological Impact of Nanocellulose. J. Nanobiotechnol. 2016, 14, 78. [CrossRef]

276. Frank, B.P.; Durkin, D.P.; Caudill, E.R.; Zhu, L.; White, D.H.; Curry, M.L.; Pedersen, J.A.; Fairbrother, D.H. Impact of Silanization on the Structure, Dispersion Properties, and Biodegradability of Nanocellulose as a Nanocomposite Filler. Appl. Nano Mater. 2018, 1, 7025-7038. [CrossRef]

277. Amara, C.; El Mahdi, A.; Medimagh, R.; Khwaldia, K. Nanocellulose-Based Composites for Packaging Applications. Curr. Opin. Green Sustain. Chem. 2021, 31, 100512. [CrossRef]

278. Montazeri, M.; Eckelman, M.J. Life Cycle Assessment of UV-Curable Bio-Based Wood Flooring Coatings. J. Clean. Prod. 2018, 192, 932-939. [CrossRef]

279. La Rosa, A.D.; Recca, G.; Summerscales, J.; Latteri, A.; Cozzo, G.; Cicala, G. Bio-Based versus Traditional Polymer Composites. A Life Cycle Assessment Perspective. J. Clean. Prod. 2014, 74, 135-144. [CrossRef]

280. Heidari, M.D.; Lawrence, M.; Blanchet, P.; Amor, B. Regionalised Life Cycle Assessment of Bio-Based Materials in Construction; the Case of Hemp Shiv Treated with Sol-Gel Coatings. Materials 2019, 12, 2987. [CrossRef]

281. Garcia Gonzalez, M.N.; Levi, M.; Turri, S. Development of Polyester Binders for the Production of Sustainable Polyurethane Coatings: Technological Characterization and Life Cycle Assessment. J. Clean. Prod. 2017, 164, 171-178. [CrossRef]

282. Cherubini, F.; Bird, N.D.; Cowie, A.; Jungmeier, G.; Schlamadinger, B.; Woess-Gallasch, S. Energy- and Greenhouse Gas-Based LCA of Biofuel and Bioenergy Systems: Key Issues, Ranges and Recommendations. Resour. Conserv. Recycl. 2009, 53, $434-447$. [CrossRef]

283. Schmidt, A.C.; Jensen, A.A.; Clausen, A.U.; Kamstrup, O.; Postlethwaite, D. A Comparative Life Cycle Assessment of Building Insulation Products Made of Stone Wool, Paper Wool and Flax Part 1: Background, Goal and Scope, Life Cycle Inventory, Impact Assessment and Interpretation. Int. J. Life Cycle Assess. 2004, 9, 53-66. [CrossRef]

284. Mohanty, A.K.; Misra, M.; Drzal, L.T. Sustainable Bio-Composites from Renewable Resources: Opportunities and Challenges in the Green Materials World. J. Polym. Environ. 2002, 10, 19-26. [CrossRef]

285. Joshi, S.V.; Drzal, L.T.; Mohanty, A.K.; Arora, S. Are Natural Fiber Composites Environmentally Superior to Glass Fiber Reinforced Composites? Compos. Part A Appl. Sci. Manuf. 2004, 35, 371-376. [CrossRef]

286. Ardente, F.; Beccali, M.; Cellura, M.; Mistretta, M. Building Energy Performance: A LCA Case Study of Kenaf-Fibres Insulation Board. Energy Build. 2008, 40, 1-10. [CrossRef]

287. Dodoo, A.; Gustavsson, L. Life Cycle Primary Energy Use and Carbon Footprint of Wood-Frame Conventional and Passive Houses with Biomass-Based Energy Supply. Appl. Energy 2013, 112, 834-842. [CrossRef]

288. Ürge-Vorsatz, D.; Cabeza, L.F.; Serrano, S.; Barreneche, C.; Petrichenko, K. Heating and Cooling Energy Trends and Drivers in Buildings. Renew. Sustain. Energy Rev. 2015, 41, 85-98. [CrossRef]

289. Ma, Q.; Bai, M. Mechanical Behavior, Energy-Storing Properties and Thermal Reliability of Phase-Changing Energy-Storing Concrete. Constr. Build. Mater. 2018, 176, 43-49. [CrossRef]

290. Baetens, R.; Jelle, B.P.; Gustavsen, A. Phase Change Materials for Building Applications: A State-of-the-Art Review. Energy Build. 2010, 42, 1361-1368. [CrossRef]

291. Mathis, D.; Blanchet, P.; Landry, V.; Lagière, P. Impregnation of Wood with Microencapsulated Bio-Based Phase Change Materials for High Thermal Mass Engineered Wood Flooring. Appl. Sci. 2018, 8, 2696. [CrossRef]

292. Mathis, D.; Blanchet, P.; Landry, V.; Lagière, P. Thermal Characterization of Bio-Based Phase Changing Materials in Decorative Wood-Based Panels for Thermal Energy Storage. Green Energy Environ. 2019, 4, 56-65. [CrossRef]

293. Bhatt, V.D.; Gohil, K.; Mishra, A. Thermal Energy Storage Capacity of Some Phase Changing Materials and Ionic Liquids. Int. J. ChemTech Res. 2010, 2, 1771-1779.

294. Mathis, D.; Blanchet, P.; Lagière, P.; Landry, V. Performance of Wood-Based Panels Integrated with a Bio-Based Phase Change Material: A Full-Scale Experiment in a Cold Climate with Timber-Frame Huts. Energies 2018, 11, 3093. [CrossRef]

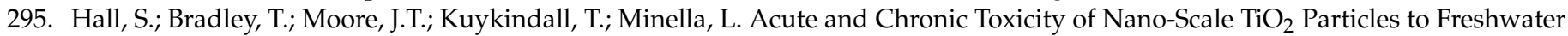
Fish, Cladocerans, and Green Algae, and Effects of Organic and Inorganic Substrate on $\mathrm{TiO}_{2}$ Toxicity. Nanotoxicology 2009, 3 , 91-97. [CrossRef]

296. Kozak, R.A.; Cohen, D.H.; Lerner, J.; Bull, G.Q. Western Canadian Consumer Attitudes towards Certified Value-Added Wood Products: An Exploratory Assessment. For. Prod. J. 2004, 54, 21-24.

297. Huang, H.Z.; Liu, Z.J.; Murthy, D.N.P. Optimal Reliability, Warranty and Price for New Products. IIE Trans. (Inst. Ind. Eng.) 2007, 39, 819-827. [CrossRef]

298. Roos, A.; Nyrud, A.Q. Description of Green versus Environmentally Indifferent Consumers of Wood Products in Scandinavia: Flooring and Decking. J. Wood Sci. 2008, 54, 402-407. [CrossRef]

299. Bigsby, H.; Ozanne, L.K. The Purchase Decision: Consumers and Environmentally Certified Wood Products. For. Prod. J. 2002, 52, 100-105.

300. Nyrud, A.Q.; Roos, A.; Rødbotten, M. Product Attributes Affecting Consumer Preference for Residential Deck Materials. Can. J. For. Res. 2008, 38, 1385-1396. [CrossRef]

301. Jonsson, O.; Lindberg, S.; Roos, A.; Hugosson, M.; Lindström, M. Consumer Perceptions and Preferences on Solid Wood, Wood-Based Panels, and Composites. Wood Fiber Sci. 2008, 40, 663-678. 
302. Sedliačiková, M.; Moresová, M.; Aláč, P.; Malá, D. What Is the Supply and Demand for Coloured Wood Products? An Empirical Study in Slovakian Practice. Forests 2021, 12, 530. [CrossRef]

303. Bernard, A.; Gélinas, N.; Duchateau, E.; Durocher, C.; Achim, A. American Beech in Value-Added Hardwood Products: Assessing Consumer Preferences. BioResources 2019, 13, 6893-6910. [CrossRef]

304. Fang, W.; Guo, H.Y.; Li, B.; Li, Q.; Feng, X.Q. Revisiting the Critical Condition for the Cassie-Wenzel Transition on MicropillarStructured Surfaces. Langmuir 2018, 34, 3838-3844. [CrossRef] [PubMed] 